\title{
C5-Substituted 2-Selenouridines Ensure Efficient Base Pairing with Guanosine; Consequences for Reading the NNG-3' Synonymous mRNA Codons
}

\author{
Grazyna Leszczynska $^{1}$, Marek Cypryk ${ }^{2} \oplus$, Bartlomiej Gostynski ${ }^{2}$, Klaudia Sadowska $^{1}$, \\ Paulina Herman ${ }^{1}$, Grzegorz Bujacz ${ }^{3}(\mathbb{D})$, Elzbieta Lodyga-Chruscinska ${ }^{4}\left(\mathbb{D}\right.$, Elzbieta Sochacka ${ }^{1}(\mathbb{D})$ \\ and Barbara Nawrot $2, *$ (D) \\ 1 Institute of Organic Chemistry, Faculty of Chemistry, Lodz University of Technology, Zeromskiego 116, \\ 90-924 Lodz, Poland; grazyna.leszczynska@p.lodz.pl (G.L.); klaudia.sadowska@edu.p.lodz.pl (K.S.); \\ 197394@edu.p.lodz.pl (P.H.); elzbieta.sochacka@p.lodz.pl (E.S.) \\ 2 Centre of Molecular and Macromolecular Studies, Polish Academy of Sciences, Sienkiewicza 112, \\ 90-363 Lodz; Poland; mcypryk@cbmm.lodz.pl (M.C.); bgostyns@cbmm.lodz.pl (B.G.) \\ 3 Institute of Molecular and Industrial Biotechnology, Lodz University of Technology, 4/10 Stefanowskiego St., \\ 90-924 Lodz, Poland; grzegorz.bujacz@p.lodz.pl \\ 4 Institute of General Food Chemistry, Lodz University of Technology, 4/10 Stefanowskiego St., \\ 90-924 Lodz, Poland; elzbieta.lodyga-chruscinska@p.lodz.pl \\ * Correspondence: bnawrot@cbmm.lodz.pl; Tel.: +48-42-6803248
}

Received: 31 March 2020; Accepted: 18 April 2020; Published: 20 April 2020

\begin{abstract}
Substituted 2-selenouridines (R5Se2U) are post-transcriptional modifications present in the first anticodon position of transfer RNA. Their functional role in the regulation of gene expression is elusive. Here, we present efficient syntheses of 5-methylaminomethyl-2-selenouridine (1, mnm5Se2U), 5-carboxymethylaminomethyl-2-selenouridine (2, cmnm5Se2U), and Se2U (3) alongside the crystal structure of the latter nucleoside. By using $\mathrm{pH}$-dependent potentiometric titration, $\mathrm{pKa}$ values for the $\mathrm{N} 3 \mathrm{H}$ groups of 1-3 were assessed to be significantly lower compared to their 2-thio- and 2-oxo-congeners. At physiological conditions ( $\mathrm{pH}$ 7.4), Se2-uridines $\mathbf{1}$ and $\mathbf{2}$ preferentially adopted the zwitterionic form (ZI, ca. 90\%), with the positive charge located at the amino alkyl side chain and the negative charge at the Se2-N3-O4 edge. As shown by density functional theory (DFT) calculations, this ZI form efficiently bound to guanine, forming the so-called "new wobble base pair", which was accepted by the ribosome architecture. These data suggest that the tRNA anticodons with wobble R5Se2Us may preferentially read the $5^{\prime}$-NNG-3' synonymous codons, unlike their 2-thio- and 2-oxo-precursors, which preferentially read the $5^{\prime}$-NNA-3' codons. Thus, the interplay between the levels of U-, S2U- and Se2U-tRNA may have a dominant role in the epitranscriptomic regulation of gene expression via reading of the synonymous $3^{\prime}-\mathrm{A}-$ and $3^{\prime}-\mathrm{G}-$ ending codons.
\end{abstract}

Keywords: modified uridine; wobble modification; seleno-uridine; selenium; tRNA; anticodon; synonymous codons; translation regulation; decoding; new wobble base pair

\section{Introduction}

Presently known transfer RNAs contain more than 100 modified nucleosides, which constitute the vast majority of the 160 total modified units identified thus far in cellular RNAs. Approximately $50 \%$ of them are present at position 34 of tRNAs, also known as the wobble position of the anticodon [1,2]. They are involved in the fine-tuning of protein biosynthesis through modulation of codon-anticodon interactions and enhance the capability of tRNA to select the appropriate synonymous mRNA codon [3-7]. 5-Substituted uridines (R5Us), 2-thiouridines (R5S2Us) and 
2-selenouridines (R5Se2Us) are the most widespread types of modified wobble nucleosides and are present in all three domains of life. To date, sulfur- and selenium-containing uridines have been found only in anticodons of tRNA iso-acceptors specific for glutamate, glutamine, and lysine [8]. Four selenium-containing uridines, namely, 5-methylaminomethyl-2-selenouridine (mnm5Se2U, 1), 5-carboxymethylaminomethyl-2-selenouridine (cmnm5Se2U, 2), 2-selenouridine (Se2U, 3), and 5-aminomethyl-2-selenouridine (nm5Se2U, 4), were identified in bacterial tRNAs (Figure 1), with mnm5Se2U (1) being the most abundant [1,9-12]. Se-containing tRNAs were also found in mammalian cells (mouse leukemia cells [13], bovine liver cells [14]), archaea (Methanococcus vannielii) [15,16], and plants (germinating barley [17], Chlamydomonas, wild carrot, tobacco, bamboo, and rice cells as well as mung bean and soybean seedlings [18]), although the exact locations of Se atoms have not been described thus far.

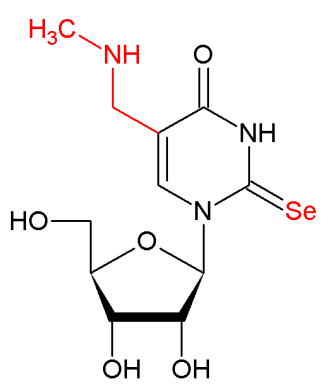

1

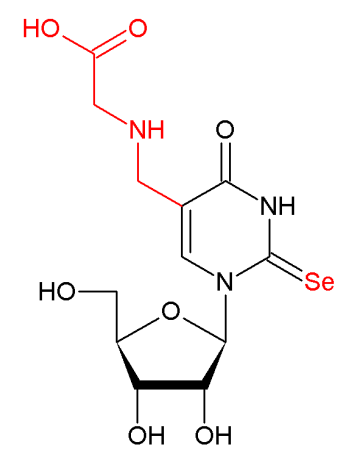

2

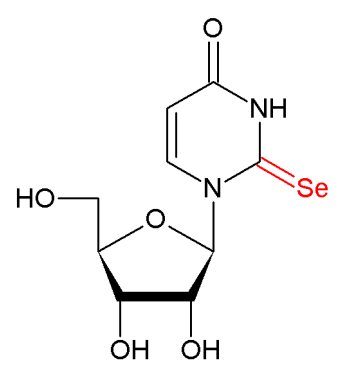

3

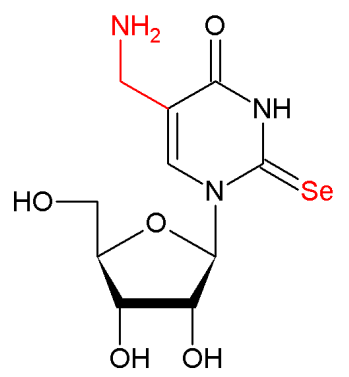

4

Figure 1. Structure of 2-selenouridine units naturally occurring in the wobble position of transfer RNA iso-acceptors specific for Lys, Glu, and Gln: 5-methylaminomethyl-2-selenouridine (mnm5Se2U, 1), 5-carboxymethylaminomethyl-2-selenouridine (cmnm5Se2U, 2), 2-selenouridine (Se2U, 3), and 5-aminomethyl-2-selenouridine (nm5Se2U, 4).

The biosynthesis pathway of 2-selenouridines in bacterial tRNAs was initially considered to be similar to that of the $\mathrm{U} \rightarrow \mathrm{S} 2 \mathrm{U}$ conversion, i.e., the deselenation of L-selenocysteine (Sec) by the selenium-specific analogue of cysteine desulfurase (lscS) [19], followed by incorporation of selenium into uridine through the action of a 2-selenouridine-specific synthetase, which was assumed to be analogous to 2-thiouridine synthetase (MnmA) [20]. According to a later proposal, bacteria synthesize selenium-modified tRNAs using the selenophosphate anion [11] (as a donor of Se) and the corresponding 2-thio precursors in a reaction catalyzed by tRNA 2-selenouridine synthase (SelU or $\mathrm{MnmH})$, which is the product of $y b b B$ gene expression in Escherichia coli $[11,21]$. YbbB orthologues were also identified in mammals [14] and archaea (Methanococcus maripaludis) [22]. Interestingly, in numerous bacteria (Escherichia coli, Enterobacter aerogenes, Pseudomonas aeruginosa, and Salmonella enterica var. Typhimurium), along with the selenium-modified uridine, $S$-geranylated derivatives of 2-thiouridine (mnm5geS2U and cmnm5geS2U) were found, although in relatively low abundance (up to 7\%) [21,23]. As noted recently, tRNA 2-selenouridine synthase SelU, i.e., the enzyme responsible for $\mathrm{S} \rightarrow$ Se replacement, also catalyzes the $S$-geranylation of 2-thiouridine in tRNAs. Contrary to earlier suggestions, it was recently demonstrated that $S$-geranylated tRNA primarily acts as the intermediate in S2U-tRNA $\rightarrow$ Se2U-tRNA transformation [24,25] and does not seem to serve as an amino acid carrier at the ribosome or bind to bacterial cell membranes $[21,23,26]$.

For many years, synthetic 2 -selenouridine nucleosides were barely accessible. The first method to attempt this achievement was based on the glycosylation of silylated 2-selenouracil, by which 2-selenouridine (Se2U, 3) [27] and 5-methylaminomethyl-2-selenouridine (mnm5Se2U, 1) [10] were obtained in low coupling yield. The second method, which was slightly more effective, was based on 2-Se functionalization of iso-cytidine with highly toxic $\mathrm{H}_{2} \mathrm{Se}$ [28]. Currently, the most effective strategy of 2-selenium incorporation relies on $S$-alkylation ( $S$-methylation or S-geranylation) of 
sugar-protected 2-thiouridine, followed by thioalkyl $\rightarrow$ SeH substitution with sodium hydrogen selenide $(\mathrm{NaSeH})[24,29,30]$. Consequently, effective synthesis of a phosphoramidite derivative of suitably protected Se2U was developed, and numerous synthetic Se2U-RNAs were obtained for structural, physicochemical and functional studies $[25,29,30]$. Huang and co-workers, who pioneered the chemical synthesis of various Se-derivatives of nucleic acids [31], also developed enzymatic synthesis of Se2U-RNAs utilizing 2-selenouridine triphosphate (Se2UTP) and RNA transcription [32].

In terms of structural properties, $\mathrm{S} 2 \mathrm{U}$ and Se2U are significantly different from uridine because the $\mathrm{S}$ and Se atoms have much larger bonding atomic radii (1.05 $\AA$ and $1.20 \AA$, respectively) than oxygen $(0.66 \AA)$. Increasing the repulsive interactions between the chalcogen atom at the $C 2$ of nucleobase and the 2'-hydroxyl group of the ribose ring is thought to lead to an increased abundance of the $\mathrm{C}^{\prime}$-endo conformation of the sugar ring (53\% in uridine, $71 \%$ in 2-thiouridine, and $80 \%$ in 2-selenouridine) [30,33-36]. The larger size of sulfur and selenium atoms also strengthens the stacking interactions between the given nucleoside and the neighboring nucleobases in RNA duplexes [29].

Regarding the specificity of hybridization, uridines in the RNA chain preferentially recognize A by Watson-Crick interactions and, with lower affinity, read G complements by wobble hydrogen bond patterns [37]. Introduction of sulfur or selenium atoms at position 2 of uridine enhances the thermodynamic stability of RNA duplexes with $\mathrm{X} 2 \mathrm{U}-\mathrm{A}$ base pairs and restricts the formation of X2U-G base pairs ( $X=S$ or Se); this effect is more pronounced for Se2U than for S2U models [29]. In contrast to the above results of thermodynamic measurements, biological experiments demonstrated that synonymous mRNA codons with $3^{\prime}$-A- and 3'-G-ending units are equally well recognized by tRNAs with anticodons containing wobble modified uridines, especially those containing sulfur at position 2 and bearing specific substituents at position 5 [20,38,39]. Recent data suggested that in a biological context (e.g., tRNA bound to mRNA at the ribosome), modified uridine 34 units $\left(\mathrm{U}^{*}{ }_{34}\right)$ can recognize guanosine units by at least two different hydrogen bonding patterns, depending on the substituents at positions 2 and 5 of the uracil ring [40-45]. While $U^{*}{ }_{34}-G$ base-pairing data are available for 5 -substituted uridines and 2-thiouridines, data for corresponding 5 -substituted 2-selenouridines identified in tRNAs are limited [46,47].

The ultimate goal of the present work is to assess the binding affinity of R5Se2U to A and G complements and to understand why Nature introduced selenium atoms instead of sulfur atoms in the wobble uridines of specific tRNAs. Here, we demonstrate an efficient method of synthesizing native selenium-modified uridines 5-substituted with methylaminomethyl (mnm5Se2U, 1) and carboxymethylaminomethyl (cmnm5Se2U, 2) side chains and describe their physicochemical and structural properties. Additionally, the crystallographic structure of the Se2U (3) nucleoside is discussed in light of the crystallographic data of its parent congeners, $U$ and S2U. The experiments are supported by computational investigations to analyze the base pairing of Se2-uridines with purine nucleosides. The obtained data are used to elucidate the influence of R5 and Se2 substituents on the structure of R5Se2U and its binding to $\mathrm{A} / \mathrm{G}$ and to determine which function of R5S2Us in tRNA is disabled but fully ensured by R5Se2Us to provide the reading of synonymous 5'-NNG-3' mRNA codons.

\section{Results}

\subsection{Chemistry}

Our syntheses of mnm5Se2U (1) (Scheme 1) and cmnm5Se2U (2) (Scheme 2) began with the 5-substituted 2-thiouridines 1a and 2a, respectively. 5-Methylaminomethyl-2-thiouridine (1a) with $N$-trifluoroacetyl (TFA) protection of the amine functional group at the 5-position and 5-carboxymethylaminomethyl-2-thiouridine (2a) with N-TFA protection and a 2-(trimethylsilyl)ethyl (TMSE) ester-type protecting group on the carboxylic function were obtained according to previously described procedures [48-52]. Before the S-alkylation step, substrates 1a and 2a were subjected to $5^{\prime}$-O-dimethoxytritylation and treated with methyl iodide in the presence of triethylamine in ethanol to obtain S-methylated 2-thiouridines 1c and 2c in yields of $90 \%$ and $80 \%$, respectively. The $S$-methylated 
derivative of mnm5S2U (1c) was subsequently treated with $\mathrm{NaSeH}$ (10 equivalents (equiv.)) prepared via a sodium borohydride reduction of elemental selenium (15 equiv.) in $\mathrm{EtOH}$ according to the procedure originally elaborated by Klayman and Griffin [53] and utilized by Huang's and Davis's groups to prepare 2-selenated thymidine and uridine phosphoramidites $[29,30,54]$. Since seleno-compounds are sensitive to oxygen, all the reactions were conducted under an argon atmosphere. In our work, the selenation of $S$-methylated mnm5S2U 1c was performed at room temperature for $2.5 \mathrm{~h}$, yielding $60 \%$ 2-selenouridine $1 \mathrm{~d}$. The use of a higher excess of $\mathrm{NaSeH}$ (12 equiv.) in the reaction with $S$-methylated cmnm5S2U $2 \mathrm{c}$ resulted in complete selenation after $1 \mathrm{~h}$ (TLC control), and the seleno-compound $\mathbf{2 d}$ was isolated in a yield of $84 \%$ after purification by flash column chromatography using argon overpressure.

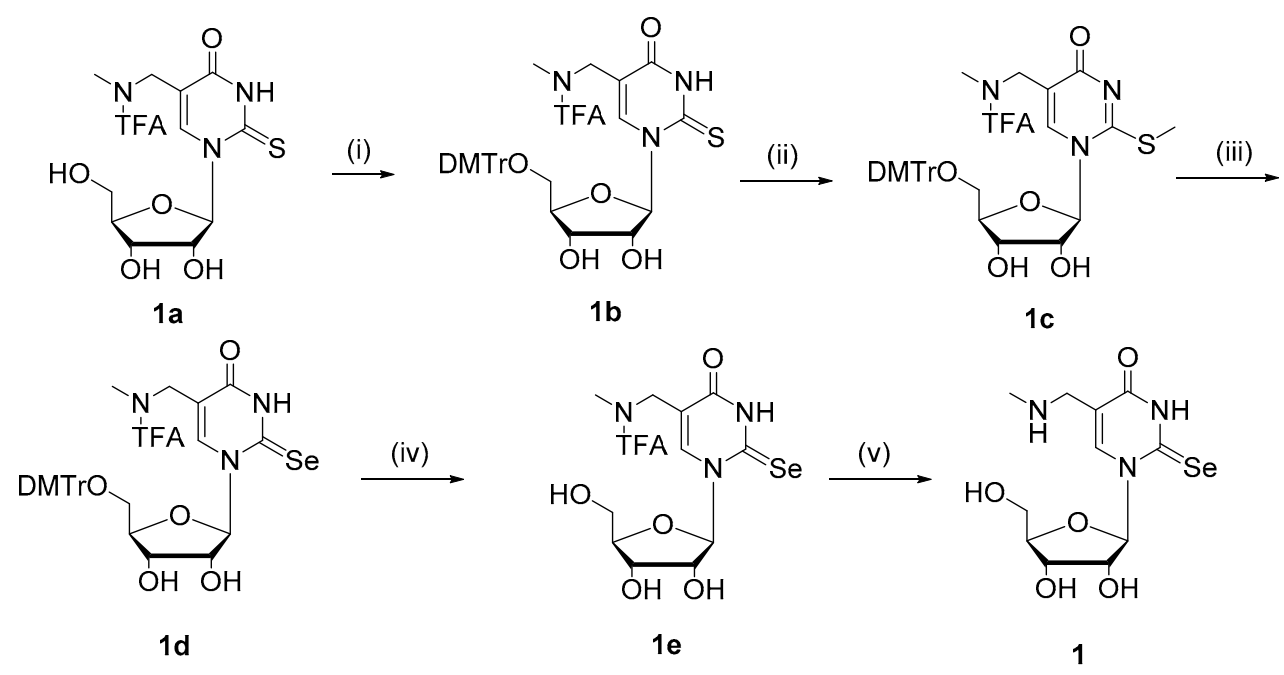

Scheme 1. Synthesis of 5-methylaminomethyl-2-selenouridine (1). Reagents and conditions: (i) DMTr-Cl, pyridine, rt, overnight, 92\%; (ii) MeI, $\mathrm{Et}_{3} \mathrm{~N}, \mathrm{EtOH}, \mathrm{rt}, 2 \mathrm{~h}, 90 \%$; (iii) Se, $\mathrm{NaBH}_{4}, \mathrm{EtOH}, 2 \mathrm{~h}$, $0{ }^{\circ} \mathrm{C}$ to generate $\mathrm{NaSeH}$, then rt, $2.5 \mathrm{~h}, 60 \%$; (iv) $50 \%$ aq. $\mathrm{AcOH}, 1.5 \mathrm{~h}, \mathrm{rt}, 70 \%$; (v) $30 \%$ aq. ammonia, $15 \mathrm{~min}, \mathrm{rt}, 83 \%$. TFA: trifluoroacetyl; DMTr: 4,4'-dimethoxytrityl.<smiles>C#CCN(CC(=O)OC)Cc1cn(C2OC(C)C(O)C(CO)O2)c(=S)[nH]c1=O</smiles>

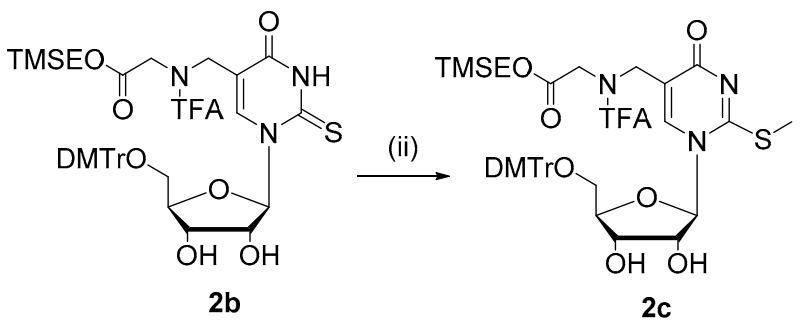

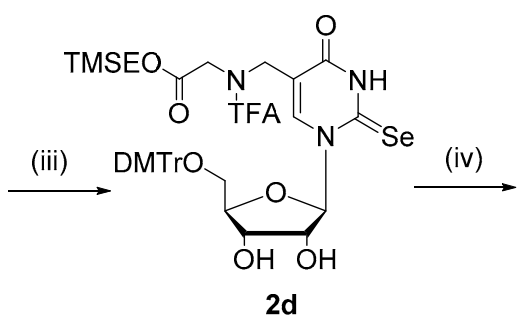

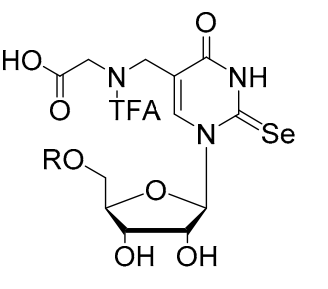

$(\mathrm{v}) \longrightarrow 2 \mathrm{e}$ R=DMTr
$\longrightarrow 2 \mathrm{f}, \mathrm{R}=\mathrm{H}$

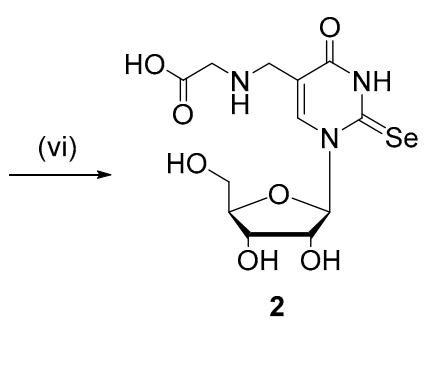

Scheme 2. Synthesis of 5-carboxymethylaminomethyl-2-selenouridine (2). Reagents and conditions: (i) DMTr-Cl, pyridine, rt, overnight, 90\%; (ii) MeI, $\mathrm{Et}_{3} \mathrm{~N}, \mathrm{EtOH}, 2 \mathrm{~h}, \mathrm{rt}, 80 \%$; (iii) Se, $\mathrm{NaBH}_{4}, \mathrm{EtOH}, 2 \mathrm{~h}$, $0{ }^{\circ} \mathrm{C}$ to generate $\mathrm{NaSeH}$, then rt, $1 \mathrm{~h}, 84 \%$; (iv) $1 \mathrm{M} \mathrm{TBAF}$ in THF, $50 \mathrm{~min}$, rt; (v) $50 \%$ aq. AcOH, $1 \mathrm{~h}, \mathrm{rt}$, 70\%; (vi) 30\% aq. ammonia, $1 \mathrm{~h}$, rt, 82\%. TFA: trifluoroacetyl; TMSE: 2-(trimethylsilyl)ethyl; DMTr: 4, $4^{\prime}$-dimethoxytrityl. 
In further steps involving the removal of protecting groups from $5^{\prime}-\mathrm{O}-\mathrm{DMTr}-\mathrm{N}$-TFAselenonucleoside $1 \mathbf{d}$ (Scheme 1), 5'-O-DMTr was removed under aqueous acidic conditions (70\% yield), then the TFA group was removed by deacylation in aqueous ammonia ( $83 \%$ yield) to give the desired selenonucleoside 1 after purification by silica gel column chromatography. The total yield of the synthesis of 2-selenouridine $\mathbf{1}$ in the four-step procedure starting from its 2-thiouridine precursor $\mathbf{1 b}$ was $31 \%$.

In the case of 5'-O-DMTr-N-TFA-TMSE-protected cmnm5Se2U 2d (Scheme 2), the carboxylic group was released in the first step using a standard $1 \mathrm{M}$ solution of tetrabutylammonium fluoride (TBAF) in THF. After $1 \mathrm{~h}$, we observed full conversion of $\mathbf{2 d}$ to carboxy-deprotected selenouridine $\mathbf{2 e}$, which exhibited significantly lower mobility on a TLC plate. To remove the excess TBAF, a sulfonic acid resin (DOWEX, form $\mathrm{H}^{+}$) and calcium carbonate were added, with methanol as a solvent [55]. After removal of the TBAF-derived material (NMR control), the crude product $\mathbf{2 e}$ was detritylated with $50 \%$ aqueous (aq.) AcOH ( $1 \mathrm{~h}$, room temperature (rt)) to obtain $2 \mathrm{f}$ in $70 \%$ yield. The ammonolysis of $N$-TFA-protected selenonucleoside $2 \mathrm{f}$ ( $30 \%$ aq. ammonium, $1 \mathrm{~h}$, rt) completed the synthesis of cmnm5Se2U (2). The final cmnm5Se2U 2 was purified by reverse phase high performance liquid chromatography (RP-HPLC) on a preparative C18 column, yielding the product at $82 \%$. The total yield of the synthesis of 2-selenouridine 2 in the four-step procedure starting from its 2-thiouridine precursor $\mathbf{2 b}$ was $38 \%$.

The structures of synthetic selenouridines $\mathbf{1}$ and $\mathbf{2}$ were fully confirmed by NMR and UV analyses (spectra presented in Supplementary Materials Figures S1-S25).

\subsection{Physicochemical Analysis}

\subsubsection{Effect of $\mathrm{pH}$ on the Structure of 2-Selenouridines 1-3 and Their Thio-Precursors 5-7}

The effect of $\mathrm{pH}$ on the structure of 2-selenouridines 1-3 and their thio-precursors 5-7 was analyzed by UV spectroscopy. The UV absorption coefficients and absorbance maxima of 2-selenouridines (1-3) and 2-thiouridines (5-7) were assessed (Table 1). Both series of UV spectra for 1-3 and 5-7, which were acquired at increasing $\mathrm{pH}$ (from $\mathrm{pH} 3$ to $\mathrm{pH}$ 8), differed significantly, as shown in Figure 2. The UV spectra of 2-selenouridines showed characteristic shifts of the absorbance maxima towards longer wavelengths at acidic, neutral, and basic $\mathrm{pH}$ in comparison to their 2-thio analogues (Figure 2, Table 1). However, both Se2- and S2-uridines exhibited the same maximum absorbance at $240 \mathrm{~nm}$ when the $\mathrm{pH}$ was changed from acidic to basic values. In the case of 5-substituted 2-selenouridines compared with 2-thiouridines, this peak exhibited higher absorbance and appeared at slightly lower $\mathrm{pH}$.

Table 1. UV absorption coefficients and absorbance maxima of 2-selenouridines 1-3 and 2-thiouridines 5-7.

\begin{tabular}{|c|c|c|c|c|c|}
\hline \multirow{2}{*}{$\begin{array}{l}\text { Comp. } \\
\text { Number }\end{array}$} & \multirow{2}{*}{$\begin{array}{c}\text { Abbreviation } \\
\text { Name }\end{array}$} & \multicolumn{3}{|c|}{$\lambda_{\max }(\mathrm{nm})$} & \multirow{2}{*}{$\varepsilon^{1}\left(\mathrm{dm}^{3} \cdot \mathrm{mol}^{-1} \cdot \mathrm{cm}^{-1}\right)$} \\
\hline & & pH 3 & pH 7 & pH 8 & \\
\hline 1 & mnm5Se2U & 223,314 & 231,302 & 240,298 & $12,669(303 \mathrm{~nm}), 6901(260 \mathrm{~nm})$ \\
\hline 2 & cmnm5Se2U & 223,314 & 231,302 & 240,298 & $12,695(310 \mathrm{~nm}), 4951(260 \mathrm{~nm})$ \\
\hline 3 & Se2U & 223,309 & 225,306 & 240,295 & $13,992(308 \mathrm{~nm}), 2687(260 \mathrm{~nm})$ \\
\hline 5 & mnm5S2U & 219,274 & 221,275 & 240,276 & $10,411(276 \mathrm{~nm}), 7283(260 \mathrm{~nm})$ \\
\hline 6 & cmnm5S2U & 221,275 & 221,275 & $223,240,277$ & $12,104(276 \mathrm{~nm}), 7645(260 \mathrm{~nm})$ \\
\hline 7 & S2U & 217,276 & 220,276 & $221,240,274$ & $14,410(276 \mathrm{~nm}), 9160(260 \mathrm{~nm})$ \\
\hline
\end{tabular}



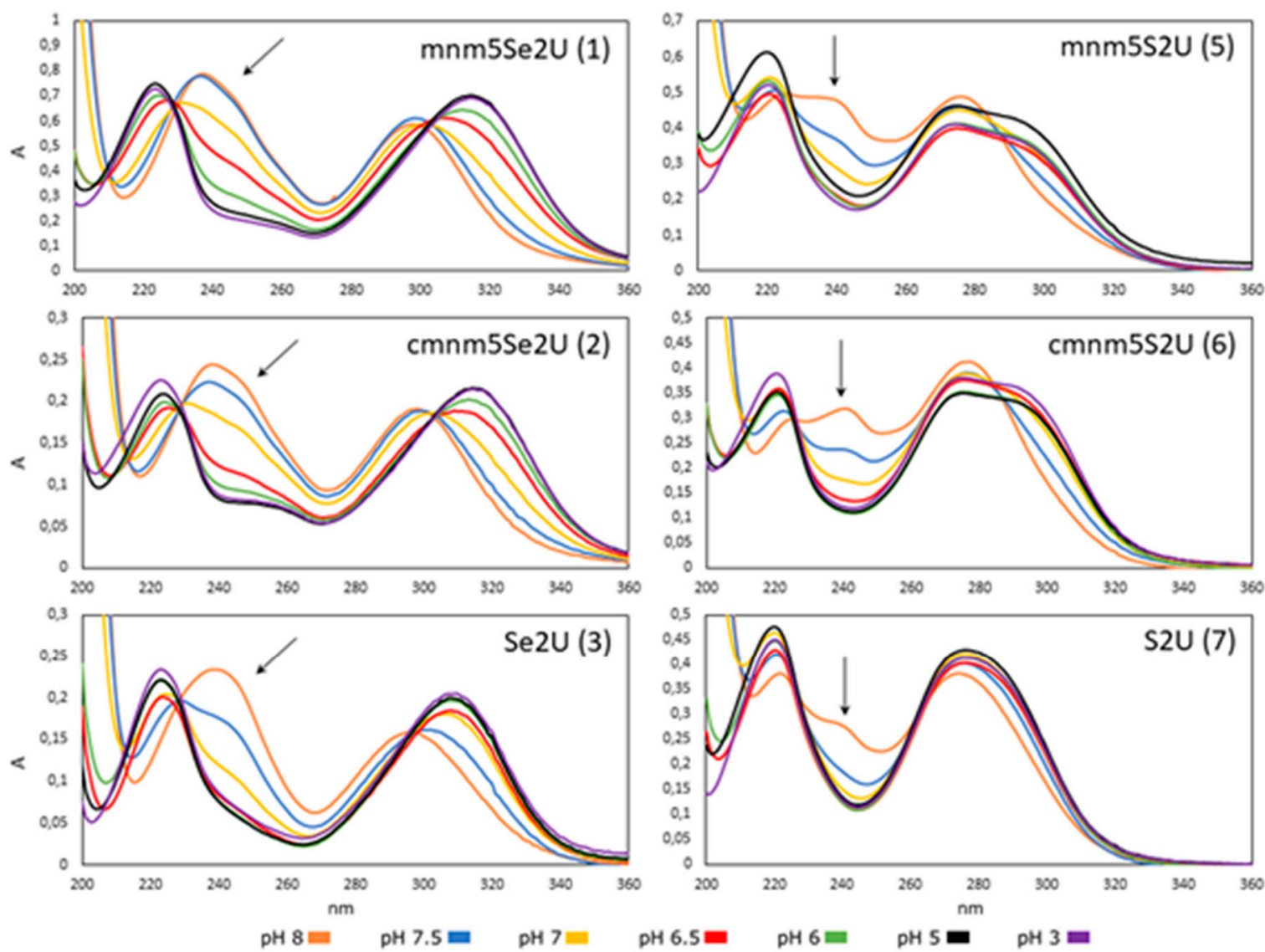

Figure 2. UV spectra of 2-selenouridines 1-3 and 2-thiouridines 5-7, taken at increasing $\mathrm{pH}$ in $10 \mathrm{mM}$ $\mathrm{HCl}$ at $\mathrm{pH} 3.0$ and $67 \mathrm{mM} \mathrm{Na}_{2} \mathrm{HPO}_{4} / \mathrm{KH}_{2} \mathrm{PO}_{4}$ buffer at $\mathrm{pH}$ 5.0, 6.0, 6.5, 7.0, 7.5, and 8.0.

\subsection{2. $\mathrm{pKa}$ Determination and Analysis of the Content of the Ionized Fraction of 1-3}

The pKa values for 2-seleno-nucleosides 1-3 (Table 2) were calculated from the respective $\mathrm{pH}$-potentiometric titration curves using an improved SUPERQUAD program [56]. For all screened compounds, the $\mathrm{pKa}$ values were obtained for their $\mathrm{N} 3 \mathrm{H}$ groups as well as for the functional groups present in the 5-side chains of $\mathbf{1}$ and $\mathbf{2}\left(-\mathrm{NHCH}_{2}\right.$ - and $\left.-\mathrm{COOH}\right)$. The $\mathrm{pKa}$ value for $\mathrm{N} 3 \mathrm{H}$ in 2-selenouridine 3 (7.30) was much lower than that for uridine (pKa 9.15) and 2-thiouridine (pKa 8.09). Furthermore, due to the presence of electron-withdrawing amino alkyl side chains, which are protonated $\left(-\mathrm{NH}_{2}{ }^{+} \mathrm{CH}_{2-}^{-}\right.$, $\mathrm{pKa}>9.0$ ) at physiological $\mathrm{pH}$, the ability of the $\mathrm{N} 3 \mathrm{H}$ proton to depart was increased. Thus, the $\mathrm{pKa}$ values of the $\mathrm{N} 3 \mathrm{H}$ groups of 1 and 2 decreased to 6.43 and 6.55, respectively. A slightly lower acidity of the $\mathrm{N} 3 \mathrm{H}$ of selenium derivative 2 was observed due to the presence of the negatively charged carboxyl group, resulting in a decrease in the electron-withdrawing character of the 5-cmnm side chain. After determining the $\mathrm{pKa}$ values of the $\mathrm{N} 3 \mathrm{H}$ groups of $\mathbf{1}, \mathbf{2}$, and $\mathbf{3}$, the content of the ionized fractions of seleno-nucleosides 1, 2, and 3 was calculated based on data obtained from the $\mathrm{pH}$-dependent potentiometric titrations, analogous to the previously used method (45). Thus, the values of ionized fractions of 1-3 at physiological $\mathrm{pH}$ (7.4) were calculated from the Henderson-Hasselbalch equation, $\mathrm{pKa}-\mathrm{pH}=\log [\mathrm{BH}] /\left[\mathrm{B}^{-}\right]$, where $\mathrm{BH}$ and $\mathrm{B}^{-}$are the neutral and ionized (deprotonated) forms, respectively [57]. The obtained results (Table 2, data given in square brackets) indicated that the 2-selenonucleoside units bearing substituents containing a positively charged protonated amino methyl group, as in $\mathbf{1}$ and 2, exist predominantly (approximately $90 \%$ ) in the N3-deprotonated (ionized) form. For the 5-unsubstituted 2-selenouridine 3, the ionized fraction was assessed to be approximately $58 \%$. Since the $\mathrm{pKa}$ values of the N3H groups in pyrimidine nucleotides (bearing a negatively charged phosphate group) were higher by approximately 0.4 units than those in the corresponding nucleosides [58], we recalculated the content of the ionized fraction of the corresponding 
nucleotides using the pKa values measured here, which increased by 0.4 units (Table 2, data given in brackets in italics). In this way, we obtained slightly lower numbers for the ionized form content, but this fraction was still predominant.

Table 2. The $\mathrm{pKa}$ values of selenonucleosides 1-3 determined by $\mathrm{pH}$-dependent potentiometric titration. The $\mathrm{pKa}$ values (determined at $25^{\circ} \mathrm{C}$ ) were assessed for the dissociation of the $\mathrm{N} 3 \mathrm{H}$ proton and for the protonation/deprotonation of the amino alkyl and carboxyl groups present in the $\mathrm{C} 5$ side chains $( \pm \mathrm{SD}=0.01)$. The content $(\%)$ of fractions of nucleosides ionized at $\mathrm{N} 3 \mathrm{H}$ at $\mathrm{pH} 7.4$ was calculated according to the Henderson-Hasselbalch equation and is given in brackets. The $\mathrm{pKa}$ data for 2-thio and 2-oxo analogues of 1-3 are cited for comparison [45].

\begin{tabular}{|c|c|c|c|c|}
\hline \multirow[b]{2}{*}{$\begin{array}{l}\text { R (Abbreviated Name } \\
\text { of the Substituent) }\end{array}$} & \multirow[b]{2}{*}{ Donor/Acceptor } & \multicolumn{3}{|c|}{ Nucleoside $^{1}$} \\
\hline & & $\mathrm{OH} \quad \mathrm{OH}$ & $\mathrm{OH} \mathrm{OH}$ & $\mathrm{OHOH}$ \\
\hline \multirow{2}{*}{$\mathrm{CH}_{3} \mathrm{NHCH}_{2}(\mathrm{mnm})$} & $\mathrm{N} 3 \mathrm{H}$ & $6.43\left(>90,78^{2}\right)$ & $7.28\left(57,34^{2}\right)$ & $8.15(15)$ \\
\hline & $\mathrm{NHCH}_{2}$ & 9.36 & 9.51 & 10.02 \\
\hline \multirow{3}{*}{$\begin{array}{c}\mathrm{HOOC}-\mathrm{CH}_{2} \mathrm{NHCH}_{2} \\
(\mathrm{cmnm})\end{array}$} & $\mathrm{N} 3 \mathrm{H}$ & $6.55\left(89,74^{2}\right)$ & $7.36\left(52,30^{2}\right)$ & $8.24(13)$ \\
\hline & $\mathrm{NHCH}_{2}$ & 8.89 & 9.10 & 10.13 \\
\hline & $\mathrm{COOH}$ & 2.26 & 2.50 & 3.05 \\
\hline $\mathrm{H}$ & $\mathrm{N} 3 \mathrm{H}$ & $7.30^{3}\left(58,34^{2}\right)$ & $8.09(17)$ & $9.15(2)$ \\
\hline
\end{tabular}

${ }^{1}$ The $\mathrm{pKa}$ values and the contents of the ionization fractions (in brackets) for 5 -substituted 2-thiouridines and uridines were taken from ref. [45]. ${ }^{2}$ The content of ionized fractions of $5^{\prime}$-phosphates of 2-seleno- and 2-thio-nucleosides, recalculated based on the $\mathrm{pKa}$ value increased by an arbitrary 0.4 units, are given in italics. ${ }^{3} \mathrm{pKa} 7.29$ for Se2U was determined by Sun et al. [29].

\subsection{Structural Analysis}

\subsubsection{Se2U Crystal Structure}

The molecular structure of 2-selenouridine (3) was determined by X-ray diffraction analysis (Figure 3). The Oak Ridge Thermal Ellipsoid Plot (ORTEP) drawing of Se2U is presented in Figure 3A. Selected crystallographic data for Se2U in comparison with S2U [59] and U [60] are given in the Supplementary Materials (Tables S1-S6). The Se2U nucleoside crystallized in one of the typical crystallographic space groups for chiral compounds, namely $\mathrm{P} 2{ }_{1}$, with one molecule in the asymmetric unit (Table S1). The crystal packing, reflected in the unit cell dimensions with a relatively short a axis, was stabilized by four intermolecular hydrogen bonds (Figure 3B, Table S2). The geometry of the 2-selenouracil heterobase moiety of Se2U was slightly changed in comparison to those of the 2-thiouracil or uracil residues in the S2U [59] and U structures [60]. The Se atom was displaced out of the heterobase ring plane by $0.234 \AA$, while the $\mathrm{S}$ atom in S2U and the $\mathrm{O}$ atom in $\mathrm{U}$ exhibited planar alignments (Table S2). The length of the C2-Se bond (1.851(8) $\AA$ ) in the Se2U molecular structure corresponds to neither a pure $\mathrm{C}=\mathrm{Se}$ bond $(1.74 \AA)$ nor a single C-Se bond (1.94 $\AA$ ) [61]. The selenol tautomer (C2-SeH), however, was rejected by crystallographic refinement; when hydrogen was modeled in place of the higher residual peak in the vicinity of the selenium atom and removal of the N3 hydrogen, the refinement parameters increased significantly. 


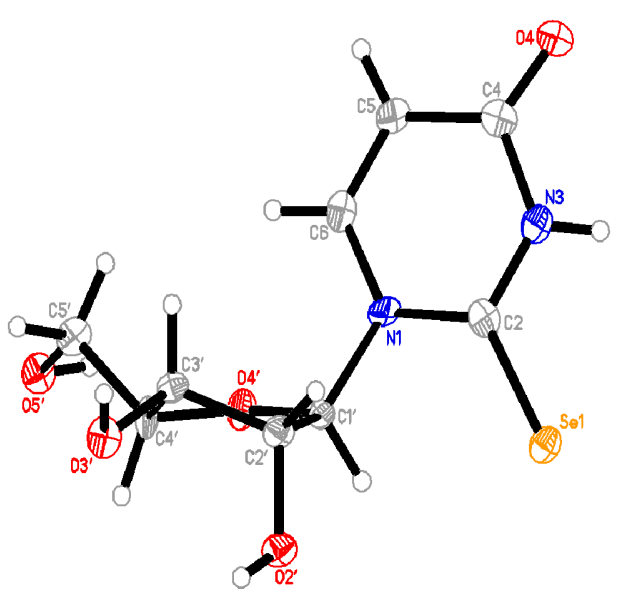

(a)

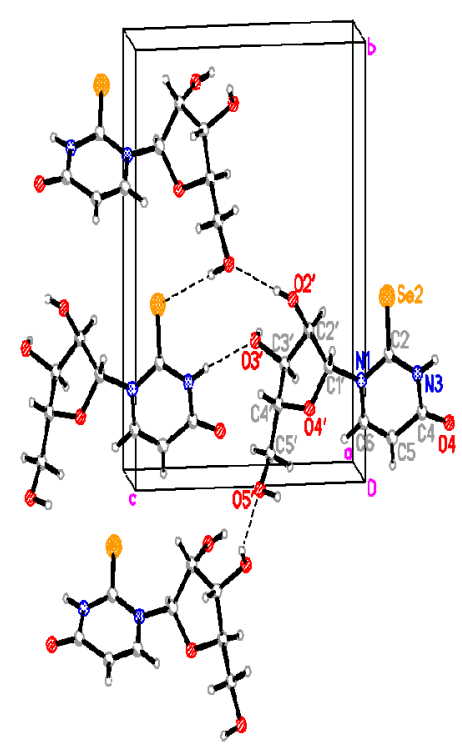

(b)

Figure 3. The ORTEP drawing of 2-selenouridine (Se2U, 3) (A) and the crystal packing of the nucleoside viewed along the $a$ axis (B). Hydrogen bonds are indicated by dashed lines. Hydrogen atoms are represented by circles with an arbitrary radius. Displacement ellipsoids were drawn at the $50 \%$ probability level.

Conformational analysis of 2-selenouridine (3) was carried out based on general parameters defined by Altona and Sundaralingam [62]. The selected torsion angles for Se2U and 2-thiouridine [59] and two crystals of uridine (A and B) [60], which are crucial for nucleoside conformation assignments, are listed in Table S6, while the resulting conformational data are shown in Table 3. The sugar of the Se2U residue adopted a $\mathrm{C}^{\prime}$-endo $\mathrm{N}$-conformation $\left({ }^{3} \mathrm{E}\right)$, with a phase angle of pseudorotation of $\mathrm{P}=14.4^{\circ}$ and a pseudorotation amplitude of $34.7^{\circ}$, which is often observed in the structure of RNA nucleosides and was also present in the crystal structures of the reference S2U and U nucleosides. The orientation of the heterocyclic base relative to the sugar moiety in Se2U molecules $\left(\chi=-146.5^{\circ}\right)$ was in the typical anti range, similar to the S2U and U structures (Table 3). The conformation around the $\mathrm{C}^{\prime}-\mathrm{C}^{\prime}$ ribose bond of Se2U was in trans arrangement, which is observed less frequently than the gauche $(+)$ structure in pyrimidine nucleosides which present an $\mathrm{N}$-type sugar ring pucker [63]. The preference of Se2U to exist as the $\mathrm{C}^{\prime}{ }^{\prime}-\mathrm{C}^{\prime}$ trans conformer is due to the hydrogen bonds involving the $5^{\prime}-\mathrm{OH}$ sugar group, similar to the hydrogen bond pattern displayed in the crystals of the S2U molecule [59].

Table 3. Conformational crystallographic data for Se2U in comparison with 2-thiouridine (S2U) [59] and uridine (U) [60].

\begin{tabular}{ccccc}
\hline $\begin{array}{c}\text { Conformational } \\
\text { Parameters }\end{array}$ & Se2U (1) & S2U (7) & \multicolumn{2}{c}{$\mathbf{U}(\mathbf{1 0 )}$} \\
\hline $\mathrm{P}\left[{ }^{\mathrm{o}}\right]$ & $\mathbf{1 4 . 4}(\mathbf{N})$ & $9.7(\mathrm{~N})$ & $3.8(\mathrm{~N})$ & $13.9(\mathrm{~N})$ \\
$\psi_{\mathrm{m}}\left[^{\circ}\right]$ & $\mathbf{3 4 . 7}$ & 36.5 & 39.6 & 41.6 \\
Sugar moiety & $\mathrm{C} 3^{\prime}$-endo & $\mathrm{C} 3^{\prime}$-endo & $\mathrm{C} 3^{\prime}$-endo & $\mathrm{C} 3^{\prime}$-endo \\
$\mathrm{C} 4^{\prime}$-C5' bond & trans & trans & gauche $(+)$ & gauche $(+)$ \\
$\mathrm{C} 1^{\prime}-\mathrm{N} 1$ bond & anti & anti & anti & anti \\
\hline
\end{tabular}




\subsubsection{Structural Analysis of Sugar Residues of 1-3 in Solution}

The conformational preference of the ribose rings in selenouridines 1-3 in solution was experimentally confirmed by ${ }^{1} \mathrm{H}$ NMR spectroscopy and compared to data obtained for their 2-thio analogues 5-7 [35] and their uridine precursors. The sulfur modification in 2-thiouridines was shown to generally stabilize the $\mathrm{C}^{\prime}$-endo conformation of the sugar ring because of steric repulsion between the sulfur atom and the oxygen atom of the $2^{\prime}$-hydroxyl group $[33,64,65]$. Thus, the replacement of the sulfur atom with a larger selenium atom should increase the steric demand upon contact with the $2^{\prime}-\mathrm{OH}$ group and stabilize the $\mathrm{C}^{\prime}{ }^{\prime}$-endo sugar conformation even more. As shown in Table 4, only 2-selenouridine 3 exhibited an increased content of the C $3^{\prime}$-endo form (80\%) in comparison to 2 -thiouridine 7 (71\%). However, the remaining 2-selenouridines 1 and $\mathbf{2}$ adopted the $\mathrm{C} 3^{\prime}$-endo conformation at a slightly lower rate than their 2-thio-congeners 5 and $\mathbf{6}$.

Table 4. The sugar ring conformation in the series of R5-substituted $\mathrm{X} 2$-uridines (where $\mathrm{R}=\mathrm{H}, \mathrm{mnm}$, cmnm and $\mathrm{X}=\mathrm{O}, \mathrm{S}, \mathrm{Se}$ ), as determined by ${ }^{1} \mathrm{H}$ NMR measurements. The $\mathrm{C} 3^{\prime}$-endo content values (in \%) were calculated according to the equation $\mathrm{C}^{\prime}$-endo $(\%)=\left(10-\mathrm{J}_{\mathrm{H} 1^{\prime}, \mathrm{H} 2^{\prime}}\right) / 10 \times 100$.

\begin{tabular}{ccc}
\hline Compound Number & Abbreviation Name & C3'-endo (\%) \\
\hline $\mathbf{1}$ & mnm5Se2U & 72 \\
\hline $\mathbf{2}$ & cmnm5Se2U & 79 \\
\hline $\mathbf{3}$ & Se2U & 80 \\
\hline $\mathbf{5}$ & mnm5S2U & $76^{1}$ \\
\hline $\mathbf{6}$ & cmnm5S2U & $82^{1}$ \\
\hline $\mathbf{8}$ & S2U & $71^{1}$ \\
\hline $\mathbf{9}$ & mnm5U & $57^{1}$ \\
\hline $\mathbf{1 0}$ & cmnm5U & $58^{1}$ \\
\hline & U & $53^{1}$ \\
\hline
\end{tabular}

\subsection{Molecular Modeling}

To understand the specific role of selenium in nucleic acid chemistry, we used theoretical DFT calculations to model the properties of 2-selenouracil (m1mnm5Se2Ura) and its complexes with guanine and to compare the results with those of previously modeled uracil (m1mnm5Ura) and 2-thiouracil (m1mnm5S2Ura). The ribose moiety in model compounds was replaced by a methyl group to reduce the computational cost. We focused on tautomerization energy, some structural features, such as bond distances and atomic charges, and the enthalpy of base-pair formation with guanine.

\subsubsection{Structural Analysis of m1Se2Ura and $\mathrm{m} 1 \mathrm{mnm} 5 \mathrm{Se} 2 \mathrm{Ura}$ Tautomers}

We identified the same series of tautomeric forms of Se2Ura nucleobases as for 2-oxo- and 2-thio-analogues, 2,4-diketo- (K), 2-enol,4-keto- (E2), 2-keto-4-enol (E4), and the zwitterionic (ZI) form [45] (see Figure S28). Structural analysis of Se2Ura tautomers in comparison with the Ura and S2Ura tautomers revealed no significant changes in bonding parameters, except for the $\mathrm{C} 2-\mathrm{X}$ bond length and the size of the heteroatom. The series of m1R5X2Ura derivatives $(X=O, S$, and Se and $R=$ $\mathrm{H}, \mathrm{mnm}$ ) showed the same trends in variation of the $\mathrm{C} 2-\mathrm{X}$ bond lengths among tautomers, e.g., for $\mathrm{ZI}$ the length of the C2-Se bond was the longest (1.866 $\AA$ ) while the C2-S and C2-O bonds were shorter (1.726 and $1.250 \AA$, respectively, see Figure S29 and Table S7). 
2.4.2. Gibbs Free Energies of the Tautomers of 1-Methyl-2-Selenouracil and 1-Methyl-5-Methylaminomethyl-2-Selenouracil

The Gibbs free energies $(\mathrm{G})$ of the diketo $(\mathrm{K})$ and two keto-enol tautomeric forms (E2 and $\mathbf{E 4}$ ), as well as the zwitterionic forms (ZI) (Figure S28, Figure 4), were calculated in the gas phase and in aqueous solution in comparison to the 5-substituted 1-methyl-2-thiouracils reported previously [45]. The relative Gibbs free energies $\left(\Delta G_{\text {rel }}\right)$ of the m1R5Se2Ura tautomers in aqueous solution were compared with those for R5Ura and R5S2Ura and are given in Table S8. These data indicated no significant difference in relative free energies of tautomers and, consequently, in tautomer equilibria between 2-thio- and 2-seleno-uracils where $\mathrm{R} 5=\mathrm{H}$ or $\mathrm{CH}_{2} \mathrm{NHCH}_{3}$. The zwitterionic forms of mnm5X2Ura were relatively stable in solution with $\Delta \mathrm{G}_{\text {rel }}$ values of $6.3,4.8$, and $5.9 \mathrm{kcal} / \mathrm{mol}$, respectively, for $\mathrm{X}=\mathrm{O}, \mathrm{S}$, and $\mathrm{Se}$, as the charge was stabilized by strong interactions with a polar solvent. The difference between experimental and theoretical results seems to come mainly from the fact that variation of $\mathrm{pH}$ is not regarded in calculations. Experimental measurements performed in various $\mathrm{pH}$ showed that the $\mathrm{p} K_{\mathrm{a}}$ values of 1-3 and 5-9 are strongly $\mathrm{pH}$-dependent. Since the theoretical model did not take into account the $\mathrm{pH}$ effect on tautomer equilibrium, it was rather expected that the diketo-tautomers of U/S2U/Se2U nucleobases were the most stable in the conditions assessed for calculations.
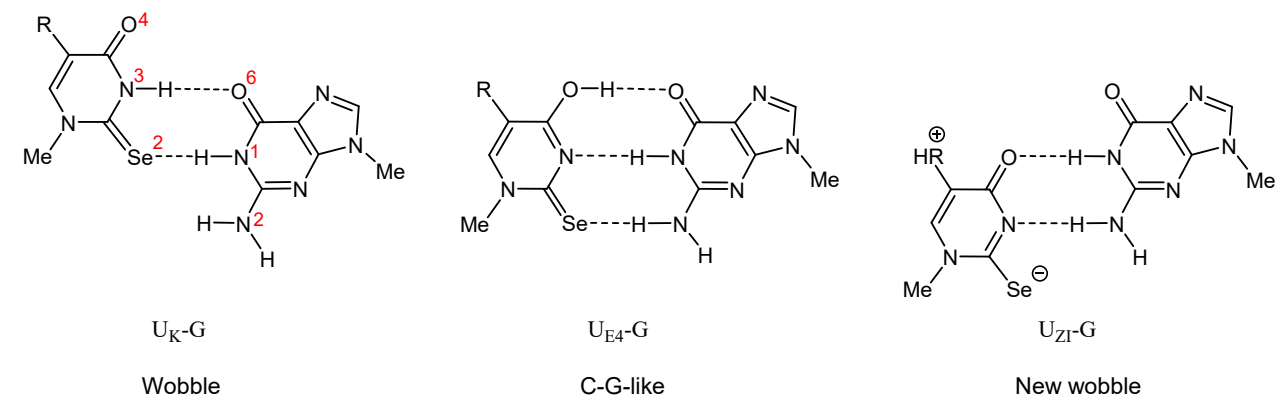

Figure 4. The structures of the complexes between m1R5Se2Ura and m9Gua. The wobble and C-G-like base pairs represent the complexes formed between the $\mathbf{K}$ and $\mathbf{E} 4$ tautomers of the pyrimidine nucleobase models and m9Gua, respectively. The new wobble base pair represents the most stable complex of the zwitterionic form of m1mnm5Se2Ura with and m9Gua (with the protonated C5-mnm side chain).

\subsubsection{Enthalpies of Base Complexation (Pairing)}

In search of energetically favoured structures displaying base pairing between the R5Se2U nucleosides and guanosine, the enthalpies of hydrogen-bonded complex formation by the most stable K, E4, and ZI tautomers of 1-methyl 5-substituted 2-selenouracils (m1R5Se2Ura, where R5 = H or mnm) with 9-methyl guanine (m9Gua) (taken in the most stable 6-keto form $[66,67]$ ) were calculated (Figure 4). The interaction enthalpies at $25^{\circ} \mathrm{C}\left(\Delta \mathrm{H}^{298}\right)$ were reported relative to those of the fully optimized isolated bases in solution (Table 5) [68]. For a given base pair, $\Delta \mathrm{H}^{298}$ was calculated according to the following equation: $\Delta \mathrm{H}^{298}=\mathrm{H}^{298}(\mathbf{U}-\mathbf{G})-\left(\mathrm{H}^{298}(\mathbf{U})+\mathrm{H}^{298}(\mathbf{G})\right)+$ BSSE, where $\mathrm{H}^{298}(\mathbf{U}-\mathbf{G})$ is the enthalpy of the optimized $\mathbf{U}-\mathbf{G}$ base pair and $\mathrm{H}^{298}(\mathbf{U})$ and $\mathrm{H}^{298}(\mathbf{G})$ are the enthalpies of the isolated and optimized $\mathbf{U}$ and $\mathbf{G}$ bases used in these studies, that is, $\mathbf{U}=\mathrm{m} 1 \mathrm{R} 5 \mathrm{Ura} / \mathrm{m} 1 \mathrm{~S} 2 \mathrm{Ura}$ and $\mathbf{G}=\mathrm{m} 9 \mathrm{Gua}$, in their most stable (canonical) tautomeric forms. Thus, for $\mathrm{U}_{\mathrm{E} 2}-\mathrm{G}, \mathrm{U}_{\mathrm{E} 4}-\mathrm{G}$, and $\mathrm{U}_{\mathrm{ZI}}-\mathrm{G}$ complexes, the given $\Delta \mathrm{H}$ values include also the enthalpy of pre-structurization of the most stable corresponding $\mathbf{K}$ tautomer into the higher energy $\mathbf{E 2}, \mathbf{E 4}$, or $\mathbf{Z I}$ forms. This is the same procedure as that applied in our previous paper [45], allowing the direct comparison of the stabilities of various complexes of particular uracil derivatives with 9-methyl-guanine. The deformation enthalpy (i.e., the enthalpy required to adjust the isolated and relaxed bases to the geometry of the base pair) was ignored in these calculations. However, for most of the base pairs, the optimization led to structures that were fairly close to planar. 
Due to base stacking and steric reasons, the base pairs in the duplexes were probably forced to adopt a more planar arrangement, thereby resulting in additional reduction of the interaction energy [69].

Table 5. Enthalpies of formation of the complexes of 9-methyl guanine (m9Gua) and modified uracils (m1R5X2Ura, where $X=\mathrm{O}, \mathrm{S}$, Se) in water calculated using the CPCM-B3LYP-GD3/6-311++G(3df,2p)//B3LYP/6-31+G(d) method (in kcal/mol). The corresponding structures of the base pairs are shown in Figure 4.

\begin{tabular}{|c|c|c|c|c|c|c|c|}
\hline \multirow{3}{*}{$\begin{array}{l}\text { Base Pair } \\
\text { Mode }\end{array}$} & \multicolumn{7}{|c|}{$\Delta \mathrm{H}^{298}$ of a Base Pair of m9Gua with m1R5X2Ura Component (kcal/mol) } \\
\hline & \multicolumn{2}{|l|}{ R5 } & \multicolumn{2}{|l|}{$\mathbf{H}$} & \multicolumn{3}{|c|}{ mnm } \\
\hline & $\mathbf{X}$ & $\mathrm{O}^{1}$ & $S^{1}$ & Se & $\mathrm{O}^{1}$ & $\mathbf{S}^{\mathbf{1}}$ & Se \\
\hline \multicolumn{2}{|c|}{$\mathbf{U}_{\mathbf{K}}-\mathrm{G}$ (wobble) } & -10.0 & -8.1 & -7.9 & -10.2 & -8.4 & -8.4 \\
\hline \multicolumn{2}{|c|}{$\mathrm{U}_{\mathrm{E} 4}-\mathrm{G}$ (C-U-TG-like) } & -7.8 & -6.6 & -6.2 & -7.6 & -6.4 & -6.8 \\
\hline \multicolumn{2}{|c|}{$\mathrm{U}_{\mathrm{ZI}}-\mathrm{G}$ (new wobble) } & - & - & - & -5.9 & -7.3 & -8.6 \\
\hline
\end{tabular}

Comparison of bonding enthalpy orders shows that in the case of 2-oxo- and 2-thio-models the $\mathrm{U}_{\mathrm{K}}-\mathrm{G}$ complex was the preferred binding mode. For the Se2 model, the enthalpies of wobble and C-G-like binding modes were almost exactly the same as for S2 model, but the "new wobble" bonding was significantly stronger than in the S2 case. Even taking into account the inaccuracy of the computational method, this difference strongly suggested that this was the preferred mode of binding of zwitterionic mnm5Se2Ura.

\subsubsection{Atomic Charge Distribution (ESP, Merz-Kollman Scheme) in Water}

Electrostatic potential-derived (ESP) atomic charges were fitted to the electrostatic potential at points selected according to the Merz-Singh-Kollman scheme [70]. ESP charges located on the C2 and $\mathrm{X}(\mathrm{X}=\mathrm{O}, \mathrm{S}, \mathrm{Se})$ atoms are displayed in Table S7, while the calculated atomic charge distributions for all tautomers of m1Se2Ura and m1mnm5Se2Ura are shown in Figure S30. Table S7 shows that the trends in variations of atomic charges between tautomers were the same in all X2Ura nucleobases $(\mathrm{X}=\mathrm{O}, \mathrm{S}, \mathrm{Se})$. The largest $\mathrm{C} 2-\mathrm{X}$ bond polarization occurred obviously in the zwitterionic form, whereas the least polarization was observed in the C2-Se bond in the E2 tautomer. Moreover, E2 tautomers of R5Se2Ura were the only case where selenium bore a positive charge. The largest change in charge upon transformation of the $\mathbf{K}$ form to the $\mathbf{Z I}$ form occurred in nitrogen, but all nucleophilic heteroatoms increased their negative charges considerably.

To understand the differences between the selenium, sulfur, and oxygen models, the changes in ESP atomic charges on the $\mathrm{O} 4, \mathrm{~N} 3$, and $\mathrm{X} 2$ atoms in the $\mathrm{X} 2-\mathrm{C} 2-\mathrm{N} 3-\mathrm{C} 4-\mathrm{O} 4$ bonding region of the zwitterionic m1mnm5X2Ura $(X=\mathrm{O}, \mathrm{S}$, Se) were analyzed before and upon formation of the base pair with m9Gua [45]. The corresponding charge distributions on the free and bound forms of 2-oxo-, 2-thio-, and 2-seleno-uracils, presented in Figure 5 (data withdrawn from Figure S30 and ref. [45]), were compared and are displayed in Figure 6. This graph shows the change in atomic charges at the O4, N3, and chalcogen atoms (in blue, green, and brown for m1mnm5Ura, m1mnm5S2Ura, and m1mnm5Se2Ura, respectively) in the form of two neighboring bars, where the left bar represents the charge before and the right bar represents the charge after the binding to the $G$ partner. While the changes in negative charge on $\mathrm{O} 4$ and the chalcogen atom increased gradually upon binding, a dramatic charge transfer was observed at the nitrogen atom of the selenium-modified base (indicated by an arrow), much bigger $(\Delta q=0.861 \mathrm{e})$ than those observed in the sulfur-modified base $(\Delta \mathrm{q}=0.546 \mathrm{e})$ and in the uracil base $(\Delta \mathrm{q}=0.178 \mathrm{e})$. Moreover, the length of the hydrogen bond N3 ... HN2 in the models of Se2U-G base pair was shorter than the same hydrogen bond in the corresponding S2U-G and $\mathrm{U}-\mathrm{G}$ base pairs (Figure 5). 

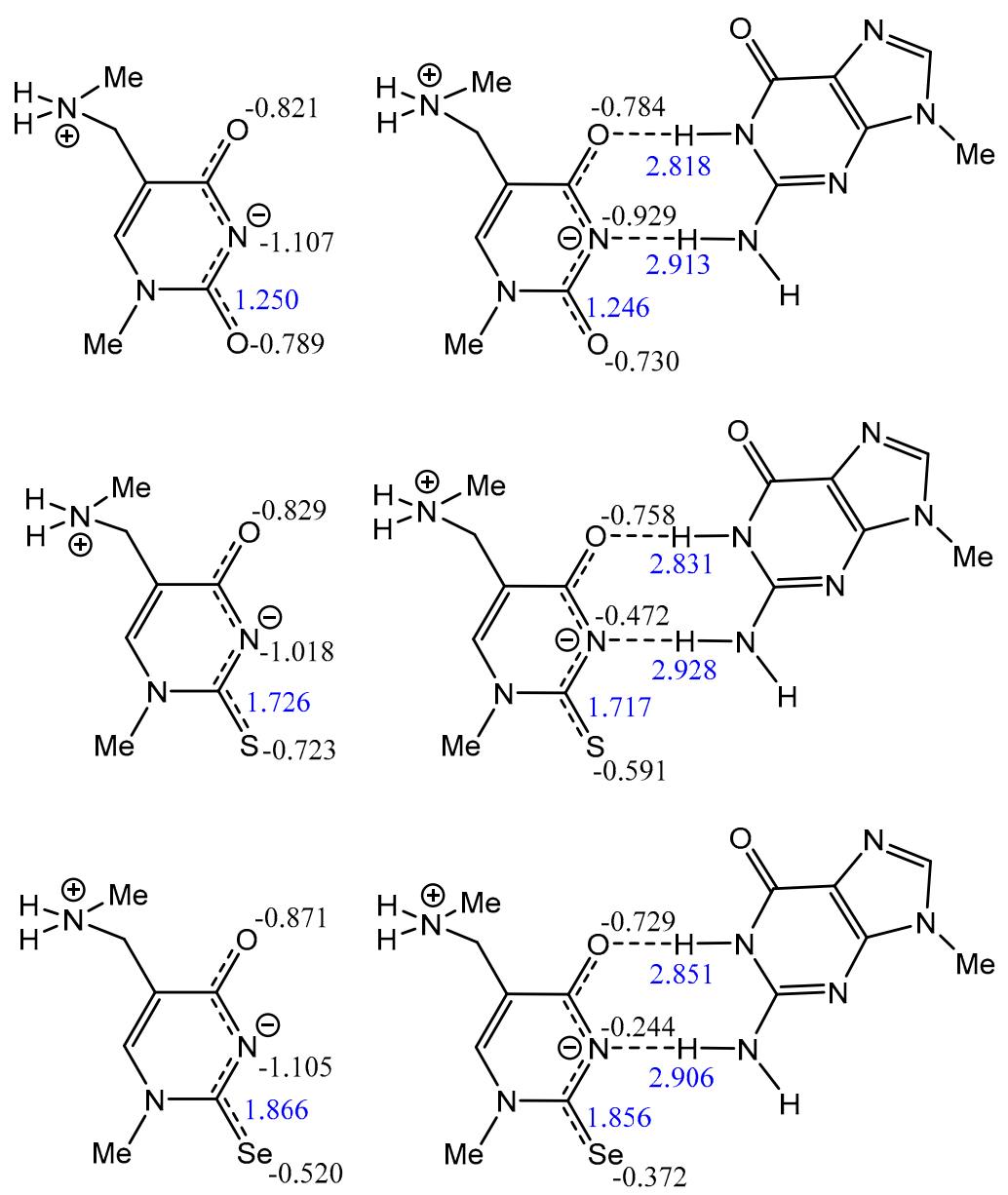

Figure 5. Comparison of selected electrostatic potential-derived (ESP) atomic charges and distances in zwitterionic m1mnm5Ura, m1mnm5S2Ura, and m1mnm5Se2Ura and in their complexes with 9-methyl guanine (m9Gua) in water; bond distances are marked in blue. The data were taken from Figure S30 and ref. [45].

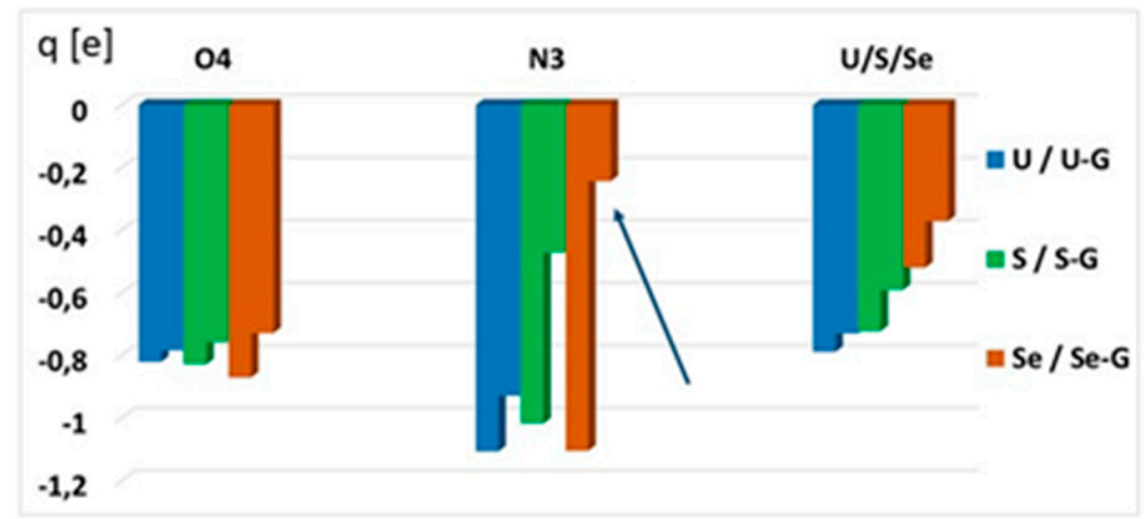

Figure 6. Comparison of the selected atomic charges on $\mathrm{O} 4, \mathrm{~N} 3$, and $\mathrm{X} 2$ atoms in zwitterionic structures of m1mnm5Ura (blue graph), -S2Ura (green graph), and -Se2Ura (brown graph) and in their complexes with m9Gua in water (as shown in Figure 5). Each graph represents the charge value at the nucleobase in a free state (left bar) and upon its binding to m9Gua (right bar). The arrow indicates the most pronounced charge transfer observed at the N3 atom of $\mathrm{m} 1 \mathrm{mnm} 5 \mathrm{Se} 2 \mathrm{U}$ upon binding to $\mathrm{m} 9 \mathrm{Gua}$; this feature distinguishes 2-Se uridines from their 2-oxo and 2-thio precursors.

The $\mathrm{X} 2 \mathrm{U} \rightarrow \mathrm{G}$ charge transfer in the base pair presents additional illustration of the differences in electron density. The charge transfer $(\Delta q)$ from the donor (zwitterionic m1mnm5X2Ura) to the acceptor 
(m9Gua) was calculated as the difference between the sum of ESP atomic charges in a given molecular fragment in the complex and the charge of the corresponding isolated molecule of nucleobase (which is zero). The charge transfer values in $\mathrm{X} 2 \mathrm{U}-\mathrm{G}$, where $\mathrm{X}=\mathrm{O}, \mathrm{S}$, or Se, are given in Table 6 . It was evident that the biggest charge transfer to m9Gua occurred upon binding of Se2U base.

Table 6. Charge transfer $m n m 5 X 2 U(Z I) \rightarrow G$ in the base pair and the difference in charge transfer $(\Delta \mathrm{q})$ in particular base pairs.

\begin{tabular}{cccc}
\hline $\mathbf{X}$ & $\mathbf{O}$ & $\mathbf{S}$ & $\mathbf{S e}$ \\
\hline Charge transfer $[\mathrm{e}]$ & 0.093 & 0.170 & 0.243 \\
\hline$\Delta \mathrm{q}=\mathrm{q}_{\mathrm{X}-\mathrm{q}_{\mathrm{O}}[\mathrm{e}]}$ & 0 & 0.077 & $\begin{array}{c}0.150\left(\mathrm{q}_{\mathrm{Se}}-\mathrm{q}_{\mathrm{O}}\right) \\
\left(\mathrm{q}_{\mathrm{Se}}-\mathrm{q}_{\mathrm{S}}\right)\end{array}$ \\
\hline
\end{tabular}

Electrostatic potential energy maps illustrating the charge distributions in the mnm5Se2U base analyzed by quantum chemical calculations were drawn up for three the most stable tautomeric forms of the $\mathrm{m} 1 \mathrm{mnm} 5 \mathrm{Se} 2 \mathrm{Ura}$ model, i.e., $\mathbf{K}, \mathbf{E} 4$, and $\mathbf{E 2}$, protonated at the amino alkyl residue; these are shown in Figure S31. The data presented for tautomers of m1mnm5Se2Ura were similar to those presented for $\mathrm{m} 1 \mathrm{mnm} 5 \mathrm{~S} 2 \mathrm{Ura}$ and $\mathrm{m} 1 \mathrm{mnm} 5 \mathrm{Ura}$ [25], demonstrating that in the zwitterionic tautomeric structure, the electron-deficient region is located in the vicinity of the ammonium cation at the side chain, while the electron-rich region is dispersed over the Se2 ... N3 ... O 4 edge. The electrostatic potential maps obtained for the three tautomeric forms of the 2-selenouracil model were consistent with those of the corresponding 2-oxo- and 2-thio-uracils [45].

\section{Discussion}

Modified nucleosides present in tRNA play a role in epitranscriptomic regulation of gene expression and allow for more accurate tuning of the translation process by restricting, expanding, or altering the decoding properties of the tRNAs. The levels of these molecules are not constant and changes in their abundance allow cells to adjust themselves in a highly dynamic manner to alterations in environmental factors, including different kinds of stress [20,71]. 5-Substituted uridines (R5Us), 2-thiouridines (R5S2Us), and 2-selenouridines (R5Se2Us) are exclusively present in a wobble position of anticodons (position 34) of tRNA specific for Glu, Gln, and Lys. Experimental and theoretical studies confirmed the regulatory function of wobble R5S2Us, which is exerted by their ability to read purine units (A and $G$ ) at the $3^{\prime}$-ends of the mRNA synonymous codons $[20,45,72,73]$. This situation is seen in all domains of life; in bacteria, the $\mathrm{C}_{34}$-sparing strategy (the lack of tRNA with $\mathrm{C}_{34}$ ) requires the presence of $\mathrm{U}_{34}$-modified tRNA ${ }^{\mathrm{Glu}}$ and tRNA ${ }^{\mathrm{Lys}}$ to be able to read the $3^{\prime}$-G-ending codon in addition to its own $3^{\prime}$-A-ending codon [3].

The combination of a sulfur atom in position 2 and an electron-withdrawing or electron-donating side chain in position 5 promotes various tautomeric forms of uracil, i.e., a 2,4-diketo form $(\mathbf{K}$ in Figure 7A,B), an E4 tautomer (Figure 7C), or a zwitterionic ZI form (Figure 7D). This "chameleon" ability explains how R5S2U hybridizes with an A complement (the $\mathbf{K}$ form) and a G complement (K, E4, or ZI forms) [44]. The latter modes (E4 and ZI) were previously demonstrated in the crystal structures of mcm5S2 $\mathrm{U}_{34}$-tRNA $\left(\mathrm{U}_{\mathrm{E} 4}-\mathrm{G}\right)$ and mnm5S2U-tRNA $\left(\mathrm{U}_{\mathrm{ZI}}-\mathrm{G}\right)$ bound to mRNA models accommodated at the ribosome [41,43], and were confirmed by physicochemical and theoretical studies [45]. In RNA duplexes, R5U/R5S2U can also recognize G units through the wobble mode (Crick hypothesis, Figure 7B) [74], although this spatial arrangement is not permitted by the ribosomal architecture [75]. 
A

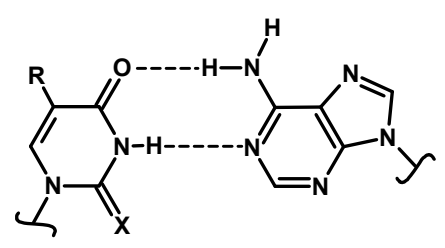

Watson-Crick U-A base pair

D

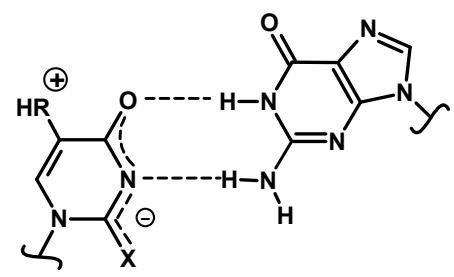

New wobble $U_{Z I}$ - $G$ base pair
B

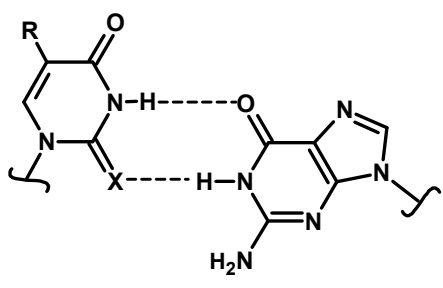

classical wobble U-G base pair

E

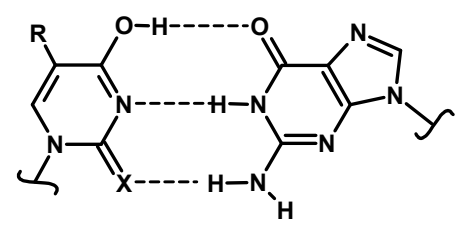

C-G like U-G base pair

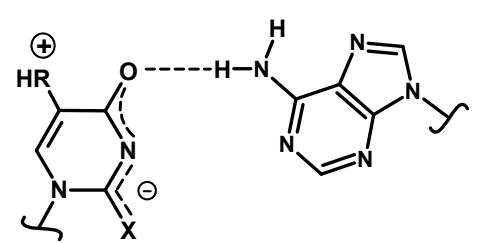

$U_{\mathrm{ZI}}$ - A base pair
$X=0, S$, Se

$\mathrm{R}=\mathrm{H}, \mathrm{mnm}, \mathrm{cmnm}$

Figure 7. Possible base-pairing schemes for 5-substituted X2U complexed with A or G.

Since R5S2Us offer at least four hybridization options, two questions arise: (1) Why did Nature develop a complex enzymatic system in bacteria (SelU, SelD, and the enzymes involved in synthesis of the geranyl component) which converts the corresponding thio-precursors 5 and $\mathbf{6}$ into 2-Se-modifications $\mathbf{1}$ and $\mathbf{2}$ in the iso-acceptor tRNAs decoding synonymous $5^{\prime}$-NNA-3' and $5^{\prime}$-NNG- ${ }^{\prime}$ codons? (2) What are the functions of R5S2Us, which are "safely" disabled due to this conversion that is apparently elicited ad hoc [25]? To have the tools necessary to answer these questions, we synthesized Se2-uridines 1-3 and compared their physicochemical and structural properties to the S2-uridine precursors 5-7, as well to the uridine parent units 8-10.

UV measurements performed for 1-3 revealed a shift of the bands at $\lambda_{\max }$ ca. $220 \mathrm{~nm}$ to $240 \mathrm{~nm}$ over a $\mathrm{pH}$ range of 6.5-7.0; this effect was slightly weaker for $\mathbf{3}$. In the spectra recorded for $\mathbf{5}$ and $\mathbf{6}$, the bands at $240 \mathrm{~nm}$ were remarkably less intense and were noted only at higher $\mathrm{pH}$ levels (7.5-8.0), whereas for 7 , only a weak shoulder was seen. We previously reported that bands around $240 \mathrm{~nm}$ may be attributed to a conjugated $\mathrm{C} 2=\mathrm{N} 3-\mathrm{C} 4=\mathrm{O} 4 \pi$-bond system present in 4-pyrimidinone-like scaffolds, e.g., in S-geranylated-2-thiouridine $\left(\lambda_{\max }\right.$ ca. $240 \mathrm{~nm}$ ) [76], 4-pyrimidinone riboside $\left(\lambda_{\max }\right.$ ca. $247 \mathrm{~nm}$ for mnm5H2U) [77], and 5-methyl-4-pyrimidinone 2'-deoxyriboside $\left(\lambda_{\max }\right.$ ca. $\left.244 \mathrm{~nm}\right)$ [78]. Thus, the observed $\mathrm{pH}$-dependent UV-shift suggested the existence of a pre-structurized tautomeric form of (c)mnm5-2-selenouridine after a transition from their classical 2,4-diketo- to the N3-deprotonated ZI-form (Figure 7).

This interpretation was supported by $\mathrm{pH}$-dependent potentiometric measurements, which showed that for R5Se2U bearing an $\mathrm{mnm}, \mathrm{cmnm}$, or $\mathrm{H}$ substituent at $\mathrm{C}$, the $\mathrm{pKa}$ values for the processes of departure of protons from the N3-H systems (e.g., pKa 6.43 for the most abundant compound 1, Table 2, Figure 8) were significantly lower compared to the corresponding S2-uridines (pKa 7.28 for 5) and uridines ( $\mathrm{pKa} 8.15$ for 8). This phenomenon originated from higher polarizability of the selenium atom compared to the sulfur or oxygen atoms $[79,80]$, and a $\Delta \mathrm{pKa}$ of 3-4 units was noted earlier for selenolates ( $\mathrm{R}-\mathrm{SeH}$ ) compared with thiolates (R-SH) [80-82]. The mnm and cmnm substituents significantly increased the acidity of the N3 hydrogen atoms in $\mathbf{1}$ and $\mathbf{2}$, respectively compared to 5-unsubstituted 3 (pKa 6.43 or 6.55 versus 7.30, respectively), because at the physiological $\mathrm{pH}(7.4)$ the amino alkyl groups were substantially protonated and both substituents acquired a strong electron-withdrawing character. Consequently, at physiological $\mathrm{pH}$ the nucleosides $\mathbf{1}$ and $\mathbf{2}$ predominantly adopted the zwitterionic form (ZI) (ca. 90\%, Table 2, data given in brackets; Figures 5 
and 7D) and, similarly to geS2U [83] and H2U units [77], their hybridization with A units might be disfavored (Figure 7E). The calculated ZI content for 5-nonsubstituted 3 was substantially lower (ca. $58 \%)$, yet similar to that for mnm5S2U (5,57\%), and much higher than for 2-thiouridine (7, 15\%). Thus, at $\mathrm{pH}$ 7.4, mnm5Se2U and cmnm5Se2U are the most prone to $\mathbf{K} \leftrightarrow \mathbf{Z I}$ pre-structurization, while $\mathbf{U}$, mnm5U, cmnm5U and S2U exist mostly in the diketo-form. Remaining mnm5S2U, cmnm5S2U, and Se2U with pKa 7.0-7.5 may preferentially adopt $\mathbf{K}$ and ZI tautomeric forms, depending on even small changes of intracellular conditions.

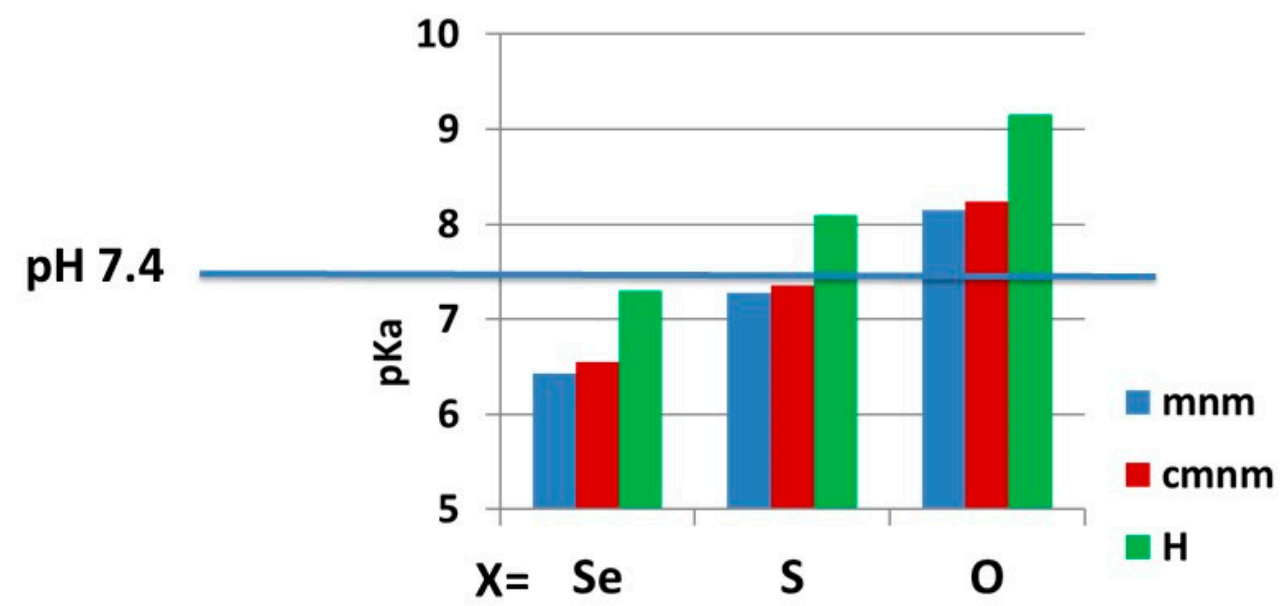

Figure 8. The $\mathrm{pKa}$ values of the $\mathrm{N} 3 \mathrm{H}$ function in $\mathrm{R} 5 \mathrm{X} 2 \mathrm{U}$ wobble modification $\mathrm{X}=\mathrm{Se}, \mathrm{S}$, or $\mathrm{O}$. The units exhibiting the $\mathrm{pKa}$ values below 7.4 at physiological $\mathrm{pH}$ values preferentially adopt the $\mathbf{Z I}$ tautomeric form and form base pairs more efficiently with the guanosine complement, while those with $\mathrm{pKa}$ values above 7.4 preferentially adopt the $\mathbf{K}$ form and preferentially form base pairs with the A partner. Nucleosides exhibiting $\mathrm{pKa}$ values around 7.4 can adopt both tautomeric forms (K and ZI) and pair with both $\mathrm{A}$ and $\mathrm{G}$ partners.

We hypothesize that the prevailing content of $\mathbf{Z I}$ forms of $\mathbf{1}$ and $\mathbf{2}$ ensure the recognition of the 3'-G-ended mRNA codons and that these Se2U-G base pairings are stronger than the S2U-G pairings delivered by $\mathbf{5}$ and $\mathbf{6}$; this was previously confirmed by functional studies [47]. Similarly, $\mathbf{5}$ and $\mathbf{6}$, besides improved reading of A, can also read G units [45]. C5-Modified Us recognize $5^{\prime}$-NNA-3' codons well, according to Watson-Crick base pairing. This "ranking" (order of appearance) is in accordance with our earlier observations, demonstrating that $\mathrm{U}_{\mathrm{ZI}}-\mathrm{G}$ base pairing decreases in the order Se2U $>$ S2U $>\mathrm{U}$. However, the exceptions are wobble uridine $\tau \mathrm{m} 5 \mathrm{U}$ and 2-thiouridine $\tau \mathrm{m} 5 \mathrm{~S} 2 \mathrm{U}$ (containing a taurinomethyl C5-side chain), which exhibit pKa values of 7.51 and 7.10, respectively, i.e., much below the values for modified uridines $\mathbf{8}$ and $\mathbf{9}$, but similar to those found for $\mathbf{5}$ and $\mathbf{6}$. These taurine modifications are supposed to allow for the reading of both $\mathrm{A}$ and $\mathrm{G}$ units in synonymous mRNA codons, while their absence causes discriminate reading of G-ended codons and results in mitochondrial genetic disorders called MEERF and MELAS [71,73].

It is worth noting that in the biological context, the X2U34 modification ( $\mathrm{X}=\mathrm{S}$, Se) has no any bias toward the $5^{\prime}$-NNA-3' codon reading executed according to the classical Watson-Crick mode of interactions (Figure 7A) [3]. On the other side, the in vitro translation experiments carried out on globin mRNA have shown that selenium-modified tRNA ${ }^{\text {Glu }}$ and $t R N A^{\text {Lys }}$ exert a stronger preference for reading the NNG over NNA codons, compared to their thio-precursors [47]. Thus, these aforementioned biological data are compatible with our pKa measurements, which indicate the preferred involvement of the zwitterionic R5Se2U in base pairing with guanosine (Figures 7D and 8).The effects of substitution of the $\mathrm{O} 2$ oxygen atom with selenium in the uracil molecule were also investigated by DFT calculations performed on m1R5X2Ura-m9Gua models $(\mathrm{R}=\mathrm{H}$ or $\mathrm{mnm}, \mathrm{X}=\mathrm{O}$, S, or Se, Figures S27-S31, Tables S7-S9). Although the atomic radius of Se and the length of the C2-Se bond were larger than those for sulfur, the enthalpies of formation for the m1Se2Ura-m9Gua and m1S2Ura-m9Gua base pairs $(\mathrm{R}=\mathrm{H})$ 
were found to be only a little different from each other $\left(\Delta \mathrm{H}^{298}\right.$ of $-7.9 \mathrm{vs}-8.1 \mathrm{kcal} / \mathrm{mol}$ for "wobble" $\mathrm{U}_{\mathrm{K}}-\mathrm{G},-6.2 \mathrm{vs}-6.6 \mathrm{kcal} / \mathrm{mol}$ for "C-G-like" $\mathrm{U}_{\mathrm{E} 4}-\mathrm{G}$, respectively) (Figure 4, Table 5). Only in the "new wobble" base pairing, in which the selenium atom does not participate directly, the difference between $\mathrm{m} 1 \mathrm{mnmSe} 2 \mathrm{U}_{\mathrm{ZI}}-\mathrm{m} 9 \mathrm{G}$ and $\mathrm{m} 1 \mathrm{mnmS2} \mathrm{U}_{\mathrm{ZI}}-\mathrm{m} 9 \mathrm{G}$ was higher $\left(\Delta \mathrm{H}^{298}-8.6 \mathrm{vs}-7.3 \mathrm{kcal} / \mathrm{mol}\right.$, respectively), thereby providing energy-based evidence that the presence of selenium in the "wobble" nucleosides makes a difference. This difference in enthalpy was most likely related to the greater polarizability of the selenium atom compared to the sulfur atom [80].

Important data were obtained from calculations of changes in electron density at the atoms in the X-C2-N3-C4-O4 bonding region of the zwitterionic form of $\mathrm{m} 1 \mathrm{mnm} 5 \mathrm{X} 2 \mathrm{Ura}(\mathrm{X}=\mathrm{O}, \mathrm{S}$, or Se) upon binding with m9Gua. The changes in the $\mathrm{O} 4$ oxygen and $\mathrm{X} 2$ atoms were small; the biggest effect was found for the Se congener. The most pronounced change was noted at the N3 atom of m1mnm5Se2Ura $(\Delta q=0.861$ e, indicated by an arrow at Figure 6), while those in the S2 and O2 congeners were ca. $60 \%$ and $20 \%$ of this value, respectively $(\Delta q=0.546 \mathrm{e}$ and $0.178 \mathrm{e})$. As a consequence, the predicted length of the (Se2U)N3-H-N2(G) hydrogen bond was the shortest compared to the base pairs bearing the S2 or O2 congeners (Figure 5). The energy of hydrogen bonds results is determined by steric, electrostatic, covalent, and dispersion interactions $[84,85]$. The charge transfer in a complex utilizing hydrogen bonds is mainly associated with the covalent (i.e., orbital interaction) contribution to the $\mathrm{H}$-bond and its increase on the $\mathrm{X}=\mathrm{O}$ to $\mathrm{X}=\mathrm{Se}$ switch is in accord with increasing bonding energy. In respect to the overall charge transfer from m1R5X2Ura to m9Gua, the biggest difference was noted for m1mnm5Se2Ura, followed by the S2 and O2 congeners (Table $6, \Delta \mathrm{q}=0.243,0.170$, and $0.093 \mathrm{e}$, respectively), suggesting that the greater polarizability of the selenium atom facilitated the transfer of electron density to guanine, resulting in stronger hydrogen bonding in the resultant base pair. The so called "new wobble" base pairing $\left(\mathrm{U}_{\mathrm{ZI}}-\mathrm{G}\right)$ was remarkably stronger in the $\mathbf{Z I}$ form than the 2-oxo- and 2-thio-analogs $(\Delta \Delta \mathrm{H}=-2.7$ and $-1.3 \mathrm{kcal} / \mathrm{mol}$, respectively, Table 5).

The molecular structure of $\mathbf{3}$ was determined by X-ray diffraction (Figure 3 ) and compared to the structures of U and S2U (Table 3, Tables S1-S6). For all three nucleosides, the expected N-type sugar ring puckering was confirmed [63] and the lengths of the $\mathrm{C} 2-\mathrm{X}$ bonds were determined at $1.227 \AA$ for uridine [60], $1.677 \AA$ for S2U (structure A [59]), and 1.851(8) $\AA$ for Se2U. The last value was remarkably different from those reported for compounds bearing a single C-Se bond (1.94 $\AA$ ) and double C-Se bond in selenones (1.74 $\AA$ ) [61]. The latter length was also exhibited by the C2-Se bond in the Se2U-A base pair (present in an RNA duplex), indicating the presence of a diketo-tautomer [29]. Se2U most likely adopted a tautomeric structure of a hybrid of 2,4-diketo- and 4-keto-2-enol forms, analogous to that of 1-mesitylimidazole-2-selone possessing a tautomerizable HN-C-Se system, for which the length of the C-Se bond was assessed as 1.845(2) $\AA$ [61]. The C-Se distance found in the crystal structure and that obtained by our DFT calculations in $\mathrm{H}_{2} \mathrm{O}$ (Figure S27) differed by only $0.03 \AA$, enhancing our confidence in the presented calculations, especially with regard to the larger value found in the crystal, which may be attributed to the intermolecular forces present in the crystal lattice.

The literature data [35] and the results of ${ }^{1} \mathrm{H}$ NMR measurements performed for 1-3 indicated that in solution, both S2 and Se2 modifications made the sugar C $3^{\prime}$-endo conformation more profound compared to $\mathrm{O} 2$ congeners (Table 4), and this feature was usually explained by steric repulsion between a relatively large S/Se atom and an $\mathrm{O}^{\prime}$ atom [86]. However, replacement of the sulfur atom with a larger selenium atom did not make the vicinity of the $2^{\prime}-\mathrm{OH}$ group in $\mathbf{1}$ and $\mathbf{2}$ more crowded (the differences were virtually negligible for $\mathbf{1} / \mathbf{5}$ and $\mathbf{2 / 6}$ ), indicating that the selenium atom operated in nucleosides conformationally similar to the $\mathrm{S} 2$ analogues. The population of the $\mathrm{C} 3^{\prime}$-endo form $(80 \%)$ was undoubtedly higher in 2-selenouridine 3 than in 2-thiouridine 7 (71\%), which may be a reason for the increased stability of the RNA duplexes containing the Se2U-A base pair [29]. 


\section{Materials and Methods}

\subsection{Chemistry}

Detailed original procedures of the synthesis of 5-methylaminomethyl-2-selenouridine (mnm5Se2U, 1) and 5-carboxymethylaminomethyl-2-selenouridine (cmnm5Se2U, 2), as well as of 2-selenouridine (Se2U, 3) and ${ }^{1} \mathrm{H}$ and ${ }^{13} \mathrm{C}$ spectra of 1, 2, 3 (for the latter also ${ }^{77}$ Se NMR spectrum) and their intermediates $\mathbf{1} \mathbf{c}-\mathbf{e}, \mathbf{2} \mathbf{c}-\mathbf{e}$ and $\mathbf{3 b}-\mathbf{c}$ (Figures S1-S25), are given in Supplementary Materials. 2-Seleno-uridines $\mathbf{1}, \mathbf{2}$, and $\mathbf{3}$ were obtained from their respective 2-thiouridine precursors $\mathbf{1} \mathbf{b}, \mathbf{2} \mathbf{b}$, and $3 a$ in several-step procedures with $31 \%$, 38\%, and 57\% total yields, respectively.

\subsection{Physicochemical Studies}

\subsubsection{The UV Measurements and Extinction Coefficients of 1, 2, and 3}

UV spectra were recorded on a Specord ${ }^{\circledR} 50$ plus spectrophotometer (Analytik, Jena, Germany). Samples were prepared by dilution of $4 \mu \mathrm{L}$ of nucleoside stock solution (ca $1 \mathrm{mg}$ of nucleoside in $1 \mathrm{~mL}$ water) in $996 \mu \mathrm{L}$ of buffer solution $\left(10 \mathrm{mM} \mathrm{HCl}\right.$ at $\mathrm{pH} 3.0,67 \mathrm{mM} \mathrm{Na}_{2} \mathrm{HPO}_{4} / \mathrm{KH}_{2} \mathrm{PO}_{4}$ buffer at $\mathrm{pH}$ $5.0,6.0,6.5,7.0,7.5,8.0)$. To determine molar extinction coefficients $(\varepsilon)$ of $\mathbf{1}-\mathbf{3}$, nucleosides of known weight were dissolved in $50 \mathrm{~mL}$ of water of $\mathrm{pH} 6.5$, then $1 \mathrm{~mL}$ of solution was transferred to a $1 \mathrm{~mL}$ quartz cell and placed in a Specord ${ }^{\circledR} 50$ plus spectrophotometer. The UV spectra were collected for three independent samples and the extinction coefficients (a mean value) were calculated from the Beer-Lambert equation using absorbance values determined for $\lambda_{\max }$ and $260 \mathrm{~nm}$.

\subsubsection{Potentiometric Measurements}

The acidity constants of the nucleosides 1-3 $(\mathrm{pKa})$ were determined by the $\mathrm{pH}$-potentiometric titration as described previously [45]. $\mathrm{pH}$-dependent $\mathrm{pKa}$ determination by UV measurements is shown in Figure S26.

\subsection{Crystallographic Analysis}

The crystals of 2-selenouridine 3 were obtained from ethanol solution in the form of thin rhombic plates, creating clusters. The plates were hard to separate and very easily cracked, therefore, the MicroMeshes loop from MiTeGen was used to separate, fish, and mount the crystal on the goniometer head. The diffraction data of 2-selenouridine crystal were collected at $100 \mathrm{~K}$ using an Oxford SuperNova diffractometer with micro-source $\mathrm{Cu} \mathrm{K} \alpha$ radiation $(\lambda=1.54 \AA)$ with a Titan detector. Diffraction data collection, cell refinement, and data reduction were performed using the CrysAlis PRO program (Oxford Diffraction). The structure was solved by direct SHELXS methods implemented into the OLEX2 package [87] and refined using full-matrix least-squares difference Fourier techniques SHELX97. Crystallographic data for 3 was deposited into the Cambridge Structural Database under accession number CCDC 1850614. The asymmetric unit contained one molecule of 2-selenouridine. The carbon and nitrogen hydrogen atoms were set geometrically and refined as riding and the hydrogen atoms connected with oxygen were found on the difference Fourier map and refined with geometrical restrains. The anisotropic thermal parameters were applied for all nonhydrogen atoms and isotropic parameters for hydrogens, equal to 1.2 of the thermal parameters of their parental atoms for geometrically restrained ones. The absolute configuration of carbon atoms of the sugar ring was determined based on the known ribose ring and confirmed by the Flack parameter -0.025(48) (classical fit to all intensities) and -0.045(27) from 850 selected quotients (Parsons' method).

\subsection{Quantum Mechanical Calculations}

DFT calculations of the relative stability of R5Se2U tautomers in water and of the binding enthalpy of R5Se2U base pairs with A and G (a model for wobble base pairing at the ribosome) were performed using Gaussian 16 suite of programs [88] using procedures analogous to those described in the previous 
paper concerning sulfur derivatives, R5S2U [45]. Geometries of the nucleic bases and base pair model systems were optimized using the hybrid B3LYP density function [89], which was corrected for dispersion interactions using the Grimme GD3 empirical term $[90,91]$ and the $6-31+G(d)$ basis set in aqueous solution. All stationary points were identified as stable minima by frequency calculations. Thermochemical corrections were scaled by a factor of 0.98 . More accurate electronic energies were obtained using the B3LYP functional, including the Grimme GD3 dispersion correction with the larger $6311++G(3 d f, 2 p)$ basis set. Calculations in solution were performed within the Conductor-like Polarizable Continuum Model (CPCM), assuming Universal Force Field (UFF) cavities [92]. Free energy of solvation was estimated using the CPCM procedure for consistency with the geometry calculations and to allow direct comparison with the previous study [45]. Atomic charges were calculated according to the Merz-Kollman scheme [70], using a covalent radius of $1.20 \AA$ for selenium [93]. The basis set superposition errors (BSSE) for the complex formation were corrected using the counterpoise procedure (CP) of Boys and Bernardi [94] at the B3LYP/6-311++G(3df,2p) level of theory. The values of error were in the range of $0.28-0.43 \mathrm{kcal} / \mathrm{mol}$ for all the complexes studied.

\section{Conclusions}

5-Methylaminomethyl- and 5-carboxymethylaminomethyl-2-selenouridine, identified in position 34 (wobble) of tRNA iso-acceptors specific for lysine, glutamine, and glutamic acid, were synthesized and their structural and physicochemical properties were investigated. $\mathrm{pH}$-dependent potentiometric measurements for the ionization of the N3H groups revealed $\mathrm{pKa}$ values lower than those for the sulfur-containing congeners, and this easier ionization most likely occurred because of higher polarizability of the selenium atom. Since at physiological pH 7.4 the amino alkyl side chains in both nucleosides were protonated (pKa ca. 9.0), the electron withdrawing effect promoted nucleosides' zwitterionic tautomeric forms. The propensity of mnm5Se2U and cmnm5Se2U for tautomerization was supported by X-ray diffraction data collected for Se2U, where the length of the C-Se bond indicated a bond order of $<2$, as was found in a hybrid of 2,4-diketo- and 4-keto-2-enol forms. The tautomers $\mathbf{E 4}$ and ZI effectively hybridized with guanosine to form the Se2U-G base pair according to "C-G-like" or "the new wobble mode", and the resultant complexes were more stable than the S2U-G and U-G base pairs. This phenomenon received convincing theoretical support from DFT calculations on three m1R5X2Ura-m9Gua models. It was found that the Se2U-G pairing was characterized by a lower binding enthalpy as well as a bigger Se $2 \mathrm{U} \rightarrow \mathrm{G}$ charge transfer compared to the S2U and $U$ congeners. These data suggested that the tRNA anticodons with wobble R5Se2Us may preferentially read the $5^{\prime}$-NNG-3' synonymous codons, unlike their 2-thio- and oxo-precursors, which preferentially read the $5^{\prime}$-NNA-3' codons, and this was actually confirmed by biological experiments with seleno-U34-tRNA [47]. Thus, the interplay between the levels of U-, S2U-, and Se2U-tRNA may have a dominant role in protein expression regulation in a situation where one $\mathrm{U}^{*}{ }_{34}$-tRNA has to decode two 3'-purine-ending synonymous codons.

Supplementary Materials: The following are available online at http://www.mdpi.com/1422-0067/21/8/2882/s1, Methods: Synthetic procedures of 1-3, protocol for potentiometric measurements. Spectral analysis of Se2U derivatives: Figures S1-S8 $-{ }^{1} \mathrm{H}$ and ${ }^{13} \mathrm{C}$ spectra of mnm5Se2U derivatives, Figures S9-S16 $-{ }^{1} \mathrm{H}$ and ${ }^{13} \mathrm{C}$ spectra of cmnm5Se2U derivatives, Figures S17-S25 - ${ }^{1} \mathrm{H},{ }^{13} \mathrm{C},{ }^{77} \mathrm{Se}$ spectra of Se2U derivatives; Figure S26 - pH-dependent pKa determination by UV measurements, Figures S27-S31 - Figures of DFT calculations, Tables S1-S6 - Data for crystal structure of Se2U, Tables S7-S9 - Data of DFT calculations.

Author Contributions: Conceptualization, B.N. and E.S.; methodology, G.L., M.C., B.G., G.B., and E.L.-C.; investigation, G.L., M.C., B.G., G.B., E.L.-C.; K.S., and P.H.; resources, B.N. and E.S.; data curation, G.L., G.B., M.C, and B.G; writing — original draft preparation, B.N., G.L, and M.C.; writing—review and editing, B.N, G.L., M.C., and E.S.; supervision, B.N.; funding acquisition, B.N. and E.S. All authors have read and agreed to the published version of the manuscript.

Funding: This research was funded by The National Science Centre in Poland (projects UMO-2014/13/B/ST5/03979 to B.N and E.S. and UMO-2018/29/B/ST5/02509 to B.N.) and by statutory funds of the Lodz University of Technology and the Centre of Molecular and Macromolecular Studies, Polish Academy of Sciences. Funding for open access charge: The National Science Centre in Poland. 
Acknowledgments: Quantum chemical DFT calculations were supported by the PL-Grid Infrastructure. The authors wish to express great admiration for the contribution of Professor Wojciech J. Stec to nucleic acid chemistry and most cordially dedicate him this work on the occasion of 80th Birthday. Thanks are directed to Dr. Piotr Guga for critical reading of the manuscript.

Conflicts of Interest: The authors declare no conflict of interest.

\section{References}

1. Boccaletto, P.; Machnicka, M.A.; Purta, E.; Piatkowski, P.; Baginski, B.; Wirecki, T.K.; de Crécy-Lagard, V.; Ross, R.; Limbach, P.A.; Kotter, A.; et al. MODOMICS: A database of RNA modification pathways. 2017 update. Nucleic Acids Res. 2017, 46, D303-D307. [CrossRef]

2. Cantara, W.A.; Crain, P.F.; Rozenski, J.; McCloskey, J.A.; Harris, K.A.; Zhang, X.; Vendeix, F.A.; Fabris, D.; Agris, P.F. The RNA Modification Database, RNAMDB: 2011 update. Nucleic Acids Res. 2011, 39, D195-D201. [CrossRef] [PubMed]

3. Grosjean, H.; de Crécy-Lagard, V.; Marck, C. Deciphering synonymous codons in the three domains of life: Co-evolution with specific tRNA modification enzymes. FEBS Lett. 2010, 584, 252-264. [CrossRef]

4. Pollo-Oliveira, L.; de Crecy-Lagard, V. Can protein expression be regulated by modulation of tRNA modification profiles. Biochemistry 2019, 58, 355-362. [CrossRef] [PubMed]

5. Krutyhołowa, R.; Zakrzewski, K.; Glatt, S. Charging the code-tRNA modification complexes. Curr. Opin. Struct. Biol. 2019, 55, 138-146. [CrossRef] [PubMed]

6. Nilsson, E.M.; Alexander, R.W. Bacterial wobble modifications of NNA decoding tRNAs. IUBMB Life 2019, 71, 1158-1166. [CrossRef]

7. Schaffrath, R.; Leidel, S.A. Wobble uridine modifications-A reason to live, a reason to die?! RNA Biol. 2017, 14, 1209-1222. [CrossRef]

8. Ching, W.M. Characterization of selenium-containing tRNAGlu from Clostridium sticklandii. Arch. Biochem. Biophys. 1986, 244, 137-146. [CrossRef]

9. Wittwer, A.J.; Stadtman, T.C. Biosynthesis of 5-methylaminomethyl-2-selenouridine, a naturally occurring nucleoside in Escherichia coli tRNA. Arch. Biochem. Biophys. 1986, 248, 540-550. [CrossRef]

10. Wittwer, A.J.; Tsai, L.; Ching, W.M.; Stadtman, T.C. Identification and synthesis of a naturally occurring selenonucleoside in bacterial tRNAs: 5-[(methylamino)methyl]-2-selenouridine. Biochemistry 1984, 23, 4650-4655. [CrossRef]

11. Wolfe, M.D.; Ahmed, F.; Lacourciere, G.M.; Lauhon, C.T.; Stadtman, T.C.; Larson; T. Functional diversity of the rhodanese homology domain: The Escherichia coli ybbB gene encodes a selenophosphate-dependent tRNA 2-selenouridine synthase. J. Biol. Chem. 2004, 279, 1801-1809. [CrossRef] [PubMed]

12. Nawrot, B.; Sochacka, E.; Duchler, M. tRNA structural and functional changes induced by oxidative stress. Cell. Mol. Life Sci. 2011, 68, 4023-4032. [CrossRef] [PubMed]

13. Ching, W.M. Occurrence of selenium-containing tRNAs in mouse leukemia cells. Proc. Natl. Acad. Sci. USA 1984, 81, 3010-3013. [CrossRef] [PubMed]

14. Mizutani, T.; Watanabe, T.; Kanaya, K.; Nakagawa, Y.; Fujiwara, T. Trace 5-methylaminomethyl2-selenouridine in bovine tRNA and the selenouridine synthase activity in bovine liver. Mol. Biol. Rep. 1999, 26, 167-172. [CrossRef]

15. Ching, W.M.; Wittwer, A.J.; Tsai, L.; Stadtman, T.C. Distribution of two selenonucleosides among the selenium-containing tRNAs from Methanococcus vannielii. Proc. Natl. Acad. Sci. USA 1984, 81, 57-60. [CrossRef]

16. Politino, M.; Tsai, L.; Veres, Z.; Stadtman, T.C. Biosynthesis of selenium-modified tRNAs in Methanococcus vannielii. Proc. Natl. Acad. Sci. USA 1990, 87, 6345-6348. [CrossRef]

17. Huang, K.X.; An, Y.X.; Chen, Z.X.; Xu, H.B. Isolation and partial characterization of selenium-containing tRNA from germinating barley. Biol. Trace Elem. Res. 2001, 82, 247-257. [CrossRef]

18. Wen, T.N.; Li, C.; Chen, C.S. Ubiquity of selenium-containing tRNA in plants. Plant Sci. 1988, 57, $185-193$.

19. Mihara, H.; Kato, S.; Lacourciere, G.M.; Stadtman, T.C.; Kennedy, R.A.; Kurihara, T.; Tokumoto, U.; Takahashi, Y.; Esaki, N. The iscS gene is essential for the biosynthesis of 2-selenouridine in tRNA and the selenocysteine-containing formate dehydrogenase H. Proc. Natl. Acad. Sci. USA 2002, 99, 6679-6683. [CrossRef] 
20. Shigi, N. Biosynthesis and functions of sulfur modifications in tRNA. Front Genet. 2014, 5, 67. [CrossRef]

21. Jäger, G.; Chen, P.; Björk, G.R. Transfer RNA bound to MnmH protein is enriched with geranylated tRNA-A possible intermediate in its selenation? PLOS ONE 2016, 11, e0153488. [CrossRef]

22. Su, D.; Ojo, T.T.; Söll, D.; Hohn, M.J. Selenomodification of tRNA in archaea requires a bipartite rhodanese enzyme. FEBS Lett. 2012, 586, 717-721. [CrossRef]

23. Dumelin, C.E.; Chen, Y.; Leconte, A.M.; Chen, Y.G.; Liu, D.R. Discovery and biological characterization of geranylated RNA in bacteria. Nat. Chem. Biol. 2012, 8, 913-919. [CrossRef] [PubMed]

24. Bartos, P.; Maciaszek, A.; Rosinska, A.; Sochacka, E.; Nawrot, B. Transformation of a wobble 2-thiouridine to 2-selenouridine via S-geranyl-2-thiouridine as a possible cellular pathway. Bioorg. Chem. 2014, 56, 49-53. [CrossRef] [PubMed]

25. Sierant, M.; Leszczynska, G.; Sadowska, K.; Komar, P.; Radzikowska-Cieciura, E.; Sochacka, E.; Nawrot, B. Escherichia coli tRNA 2-selenouridine synthase (SelU) converts S2U-RNA to Se2U-RNA via S-geranylated-intermediate. FEBS Lett. 2018, 592, 2248-2258. [CrossRef] [PubMed]

26. Chen, P.; Crain, P.F.; Näsvall, S.J.; Pomerantz, S.C.; Björk, G.R. A "gain of function" mutation in a protein mediates production of novel modified nucleosides. EMBO J. 2005, 24, 1842-1851. [CrossRef]

27. Wise, D.S.; Townsend, L.B. Synthesis of the selenopyrimidine nucleosides 2-seleno- and 4-selenouridine. J. Hetrocycl. Chem. 1972, 9, 1461-1462. [CrossRef]

28. Shiue, C.h.-Y.; Chu, S.-H. A facile synthesis of 1- $\beta$-D-arabinofuranosyl-2-seleno- and -4-selenouracil and related compounds. J. Org. Chem. 1975, 40, 2971-2974. [CrossRef]

29. Sun, H.; Sheng, J.; Hassan, A.E.; Jiang, S.; Gan, J.; Huang, Z. Novel RNA base pair with higher specificity using single selenium atom. Nucleic Acids Res. 2012, 40, 5171-5179. [CrossRef]

30. Kogami, M.; Davis, D.R.; Koketsu, M. An efficient synthesis of 2-selenouridine and its phosphoramidite precursor. Heterocycles 2016, 92, 64-74.

31. Caton-Williams, J.; Huang, Z. Biochemistry of Selenium-Derivatized Naturally Occurring and Unnatural Nucleic Acids. Chem. Biodivers. 2008, 5, 396-407. [CrossRef] [PubMed]

32. Sun, H.; Jiang, S.; Caton-Williams, J.; Liu, H.; Huang, Z. 2-Selenouridine triphosphate synthesis and Se-RNA transcription. RNA 2013, 19, 1309-1314. [CrossRef] [PubMed]

33. Sierzputowska-Gracz, H.; Sochacka, E.; Malkiewicz, A.; Kuo, K.; Gehrke, C.W.; Agris, P.F. Chemistry and structure of modified uridines in the anticodon, wobble position of transfer RNA are determined by thiolation. J. Am. Chem. Soc. 1987, 109, 7171-7177. [CrossRef]

34. Testa, S.M.; Disney, M.D.; Turner, D.H.; Kierzek, R. Thermodynamics of RNA-RNA duplexes with 2- or 4-thiouridines: Implications for antisense design and targeting a group I intron. Biochemistry 1999, 38, 16655-16662. [CrossRef]

35. Bartos, P.; Ebenryter-Olbinska, K.; Sochacka, E.; Nawrot, B. The influence of the C5 substituent on the 2-thiouridine desulfuration pathway and the conformational analysis of the resulting 4-pyrimidinone products. Bioorg. Med. Chem. 2015, 23, 5587-5594. [CrossRef]

36. Zhang, R.B.; Eriksson, L.A. Theoretical study on conformational preferences of ribose in 2-thiouridine-the role of the 2'OH group. Phys. Chem. Chem. Phys. 2010, 12, 3690-3697. [CrossRef]

37. Agris, P.F.; Sierzputowska-Gracz, H.; Smith, W.; Malkiewicz, A.; Sochacka, E.; Nawrot, B. Thiolation of uridine carbon-2 restricts the motional dynamics of the transfer RNA wobble position nucleoside. J. Am. Chem. Soc. 1992, 114, 2652-2656. [CrossRef]

38. Krüger, M.K.; Pedersen, S.; Hagervall, T.G.; Sørensen, M.A. The modification of the wobble base of tRNAGlu modulates the translation rate of glutamic acid codons in vivo. J. Mol. Biol. 1998, 284, 621-631. [CrossRef]

39. Hagervall, T.G.; Pomerantz, S.C.; McCloskey, J.A. Reduced misreading of asparagine codons by Escherichia coli tRNALys with hypermodified derivatives of 5-methylaminomethyl-2-thiouridine in the wobble position. J. Mol. Biol. 1998, 284, 33-42. [CrossRef]

40. Murphy, F.V.; Ramakrishnan, V.; Malkiewicz, A.; Agris, P.F. The role of modifications in codon discrimination by tRNA(Lys)UUU. Nat. Struct. Mol. Biol. 2004, 12, 1186-1191. [CrossRef]

41. Vendeix, F.A.P.; Murphy, F.V.; Gustilo, E.; Graham, W.; Cantora, W.; Leszczynska, G.; Sproat, B.; Malkiewicz, A.; Agris, P. Human tRNALys3UUU is pre-structured by natural modifications for cognate and wobble codon binding through keto-enol tautomerism. J. Mol. Biol. 2012, 416, 467-485. [CrossRef] [PubMed] 
42. Weixlbaumer, A.; Murphy, F.V.; Dziergowska, A.; Malkiewicz, A.; Vendix, F.A.P.; Agris, P.F.; Ramakrishnan, V. Mechanism for expanding the decoding capacity of transfer RNAs by modification of uridines. Nat. Struct. Mol. Biol. 2007, 14, 498-502. [CrossRef] [PubMed]

43. Rozov, A.; Demeshkina, N.; Khusainov, I.; Westhof, E.; Yusupov, M.; Yusupova, G. Novel base-pairing interactions at the tRNA wobble position crucial for accurate reading of the genetic code. Nat. Commun. 2016, 7, 10457. [CrossRef] [PubMed]

44. Westhof, E.; Yusupov, M.; Yusupova, G. The multiple flavors of GoU pairs in RNA. J. Mol. Recognit. 2019, 32, e2782. [CrossRef]

45. Sochacka, E.; Lodyga-Chruscinska, E.; Pawlak, J.; Cypryk, M.; Bartos, P.; Ebenryter-Olbinska, K.; Leszczynska, G.; Nawrot, B. C5-substituents of uridines and 2-thiouridines present at the wobble position of tRNA determine the formation of their keto-enol or zwitterionic forms-A factor important for accuracy of reading of guanosine at the 3'-end of the mRNA codons. Nucleic Acids Res. 2017, 45, 4825-4836. [CrossRef]

46. Stadtman, T.C. Specific occurrence of selenium in enzymes and amino acid tRNAs. FASEB J. 1987, 1, 375-379. [CrossRef]

47. Wittwer, A.J.; Ching, W.M. Selenium-containing tRNA(Glu) and tRNA(Lys) from Escherichia coli: Purification, codon specificity and translational activity. Biofactors 1989, 2, 27-34.

48. Leszczynska, G.; Pieta, J.; Leonczak, P.; Tomaszewska, A.; Malkiewicz, A. Site-specific incorporation of 5-methylaminomethyl-2-thiouridine and 2-thiouridine(s) into RNA sequences. Tetrahedron Lett. 2012, 53, 1214-1217. [CrossRef]

49. Sundaram, M.; Crain, P.F.; Davis, D.R. Synthesis and characterization of the native anticodon domain of E. coli tRNALys: Simultaneous incorporation of modified nucleosides mnm5s2U, t6A, and pseudouridine using phosphoramidite chemistry. J. Org. Chem. 2000, 65, 5609-5614. [CrossRef]

50. Leszczynska, G.; Pieta, J.; Wozniak, K.; Malkiewicz, A. Site-selected incorporation of 5-carboxymethylaminomethyl-2-thiouridine into RNA sequences by phosphoramidite chemistry. Org. Biomol. Chem. 2014, 12, 1052-1056. [CrossRef]

51. Leszczynska, G.; Leonczak, P.; Dziergowska, A.; Malkiewicz, A. mt-tRNA components: Synthesis of (2-thio)uridines modified with blocked glycine/taurine moieties at C-5,1. Nucleosides Nucleotides Nucleic Acids 2013, 32, 599-616. [CrossRef] [PubMed]

52. Davis, D.R.; Bajji, A.C. Introduction of hypermodified nucleotides in RNA. In Methods in Molecular Biology; Herdewijn, P., Ed.; Humana Press Inc.: Totowa, NJ, USA, 2005; pp. 18-204.

53. Klayman, D.L.; Griffin, T.S. Reaction of selenium with sodium borohydride in protic solvents. A facile method for the introduction of selenium into organic molecules. J. Am. Chem. Soc. 1973, 95, 197-199. [CrossRef]

54. Hassan, A.E.A.; Sheng, J.; Zhang, W.; Huang, Z. High fidelity of base pairing by 2-selenothymidine in DNA. J. Am. Chem. Soc. 2010, 132, 2120-2121. [CrossRef] [PubMed]

55. Kaburagi, Y.; Kishi, Y. Operationally simple and efficient workup procedure for TBAF-mediated desilylation: Application to halichondrin synthesis. Org. Lett. 2007, 9, 723-726. [CrossRef] [PubMed]

56. Gans, P.; Vacca, A.; Sabatini, A. SUPERQUAD: An improved general program for computation of formation constants from potentiometric data. J. Chem. Soc. Dalton Trans. 1985, 6, 1195-1200. [CrossRef]

57. De Levie, R. The Henderson-Hasselbalch Equation: Its History and Limitations. J. Chem. Educ. 2003, 80, 146. [CrossRef]

58. Takai, K.; Yokoyama, S. Roles of 5-substituents of tRNA wobble uridines in the recognition of purine-ending codons. Nucleic Acids Res. 2003, 31, 6383-6391. [CrossRef]

59. Hawkinson, S.W. The crystal and molecular structure of 2-thiouridine. Acta Cryst. B 1977, 33, 80-85. [CrossRef]

60. Green, E.A.; Rosenstein, R.D.; Shiono, R.; Abraham, D.J.; Trus, B.L.; Marsh, R.E. The crystal structure of uridine. Acta Cryst. B 1975, 31, 102-107. [CrossRef]

61. Landry, V.K.; Minoura, M.; Pang, K.; Buccella, D.; Kelly, B.V.; Parkin, G. Synthesis and structural characterization of 1-mesityl-1,3-dihydro-imidazole-2-selone and bis(1-mesitylimidazol-2-yl)diselenide: Experimental evidence that the selone is more stable than the selenol tautomer. J. Am. Chem. Soc. 2006, 128, 12490-12497. [CrossRef] 
62. Altona, C.; Sundaraligham, M. Conformational analysis of the sugar ring in nucleosides and nucleotides. New description using the concept of pseudorotation. J. Am. Chem. Soc. 1972, 94, 8205-8212. [CrossRef] [PubMed]

63. Saenger, W. Principles of Nucleic Acids Structure; Springer Verlag: New York, NY, USA, 1984; pp. 1-84.

64. Davis, D.R. Biophysical and conformational properties of modified nucleosides in RNA (nuclear magnetic resonance studies). In Modification and Editing of RNA; Grosjean, H., Benne, R., Eds.; ASM Press: Washington, DC, USA, 1998; chapter 5; pp. 85-102.

65. Larsen, A.T.; Fahrenbach, A.C.; Sheng, J.; Pian, J.; Szostak, J.W. Thermodynamic insight into 2-thiouridine-enhanced RNA hybridization. Nucleic Acids Res. 2015, 43, 7675-7687. [CrossRef] [PubMed]

66. Hanus, M.; Ryjácek, F.; Kabelác, M.; Kubar, T.; Bogdan, T.V.; Trygubenko, S.A.; Hobza, P. Correlated ab initio study of nucleic acid bases and their tautomers in the gas phase, in a microhydrated environment and in aqueous solution. Guanine: Surprising stabilization of rare tautomers in aqueous solution. J. Am. Chem. Soc. 2003, 125, 7678-7688. [PubMed]

67. Wang, W.; Hellinga, H.W.; Beese, L.S. Structural evidence for the rare tautomer hypothesis of spontaneous mutagenesis. Proc. Nat. Acad. Sci. USA 2011, 108, 17644-17648. [CrossRef]

68. Sponer, J.; Jurecka, P.; Hobza, P. Accurate interaction energies of hydrogen-bonded nucleic acid base pairs. J. Am. Chem. Soc. 2004, 126, 10142-10151. [CrossRef]

69. Mizuno, H.; Sundaralingam, M. Stacking of Crick wobble pair and Watson-Crick pair: Stability rules of G-U pairs at ends of helical stems in tRNAs and the relation to codon-anticodon wobble interaction. Nucleic Acids Res. 1978, 15, 4451-4461. [CrossRef]

70. Singh, U.C.; Kollman, P.A. An approach to computing electrostatic charges for molecules. J. Comput. Chem. 1984, 5, 129-145. [CrossRef]

71. Duchler, M.; Leszczynska, G.; Sochacka, E.; Nawrot, B. Nucleoside modifications in the regulation of gene expression: Focus on tRNA. Cell. Mol. Life Sci. 2016, 73, 3075-3095. [CrossRef]

72. Fernandez-Vazquez, J.; Vargas-Perez, I.; Sanso, M.; Buhne, K.; Carmona, M.; Paulo, E.; Hermand, D.; Rodríguez-Gabriel, M.; Ayté, J.; Leidel, S.; et al. Modification of tRNA(Lys)UUU by elongator is essential for efficient translation of stress mRNAs. PLoS Genet. 2013, 9, e1003647. [CrossRef]

73. Kurata, S.; Weixlbaumer, A.; Ohtsuki, T.; Shimazaki, T.; Wada, T.; Kirino, Y.; Takai, K.; Watanabe, K.; Ramakrishnan, V.; Suzuki, T. Modified uridines with C5-methylene substituents at the first position of the tRNA anticodon stabilize U-G wobble pairing during decoding. J. Biol. Chem. 2008, 283, 18801-18811. [CrossRef]

74. Crick, F.H. Codon-anticodon pairing: The wobble hypothesis. J. Mol. Biol. 1966, 19, 548-555. [CrossRef]

75. Westhof, E.; Yusupov, M.; Yusupova, G. Recognition of Watson-Crick base pairs: Constraints and limits due to geomet ric selection and tautomerism. F1000Prime Rep. 2014, 6, 19. [CrossRef] [PubMed]

76. Leszczynska, G.; Sadowska, K.; Bartos, P.; Nawrot, B.; Sochacka, E. S-Geranylated 2-thiouridines of bacterial tRNAs: Chemical synthesis and physicochemical properties. Eur. J. Org. Chem. 2016, 21, 3482-3485. [CrossRef]

77. Sochacka, E.; Szczepanowski, R.H.; Cypryk, M.; Sobczak, M.; Janicka, J.; Kraszewska, K.; Bartos, P.; Chwialkowska, A.; Nawrot, B. 2-Thiouracil deprived of thiocarbonyl function preferentially base pairs with guanine rather than adenine in RNA and DNA duplexes. Nucleic Acids Res. 2015, 43, 2499-2512. [CrossRef]

78. Rajur, S.B.; McLaughlin, L.W. The synthesis of oligodeoxynucleotides containing 2-thiothymine and 5-methyl-4-pyrimidinone base analogues. Tetrahedron Lett. 1992, 33, 6081-6084. [CrossRef]

79. Collins English Dictionary, 13th ed.; HarperCollins.: New York, NY, USA, 16 November 2018.

80. Reich, H.J.; Hondal, R.J. Why Nature chose selenium. ACS Chem. Biol. 2016, 11, 821-841. [CrossRef]

81. Sugiura, Y.; Hojo, Y.; Tamai, Y.; Tanaka, H. Selenium protection against mercury toxicity. Binding of methylmercury by the selenohydryl-containing ligand. J. Am. Chem. Soc. 1976, 98, 2339-2341. [CrossRef]

82. Huber, R.E.; Criddle, R.S. Comparison of the chemical properties of selenocysteine and selenocystine with their sulfur analog. Arch. Biochem. Biophys. 1967, 122, 164-173. [CrossRef]

83. Sierant, M.; Leszczynska, G.; Sadowska, K.; Dziergowska, A.; Rozanski, M.; Sochacka, E.; Nawrot, B. $S$-Geranyl-2-thiouridine wobble nucleosides of bacterial tRNAs; chemical and enzymatic synthesis of S-geranylated-RNAs and their physicochemical characterization. Nucleic Acids Res. 2016, 44, 10986-10998. [CrossRef] 
84. Guerra, C.F.; Bickelhaupt, F.M. Substituent effects on hydrogen bonds in DNA. In Computational Studies of RNA and DNA in Šponer, F. Lankaš Computational Studies of RNA and DNA; Springer: Dordrecht, The Netherlands, 2006; pp. 463-484S.

85. Van der Lubbe, S.C.C.; Guerra, C.F. Hydrogen-bond strength of CC and GG pairs determined by steric repulsion: Electrostatics and charge transfer overruled. Chem. Eur. J. 2017, 23, 10249-10253. [CrossRef]

86. Agris, P.F.; Eruysal, E.R.; Narendran, A.; Väre, V.Y.P.; Vangaveti, S.; Ranganathan, S.V. Celebrating wobble decoding: Half a century and still much is new. RNA Biol. 2018, 15, 537-553. [CrossRef] [PubMed]

87. Dolomanov, O.V.; Bourhis, L.J.; Gildea RJHoward, J.A.K.; Puschmann, H. OLEX2: A complete structure solution, refinement and analysis program. J. Appl. Crystal. 2009, 42, 339-341. [CrossRef]

88. Frisch, M.J.; Trucks, G.W.; Schlegel, H.B.; Scuseria, G.E.; Robb, M.A.; Cheeseman, J.R.; Scalmani, G.; Barone, V.; Petersson, G.A.; Nakatsuji, H.; et al. Gaussian 16, Revision B.01; Gaussian, Inc.: Wallingford, CT, USA, 2016.

89. Becke, A.D. Density-functional thermochemistry. III. The role of exact exchange. J. Chem. Phys. 1993, 98, 5648-5652. [CrossRef]

90. Grimme, S.; Antony, J.; Ehrlich, S.; Krieg, H. A consistent and accurate ab initio parameterization of density functional dispersion correction (DFT-D) for the 94 elements H-Pu. J. Chem. Phys. 2010, 132, 154104-154119. [CrossRef]

91. Antony, J.; Grimme, S. Density functional theory including dispersion corrections for intermolecular interactions in a large benchmark set of biologically relevant molecules. Phys. Chem. Chem. Phys. 2006, 8, 5287-5293. [CrossRef] [PubMed]

92. Cossi, M.; Rega, N.; Scalmani, G.; Barone, V. Energies, structures, and electronic properties of molecules in solution with the C-PCM solvation model. J. Comput. Chem. 2003, 24, 669-681. [CrossRef] [PubMed]

93. Cordero, B.; Gomez, V.; Platero-Prats, A.E.; Reves, M.; Echeverria, J.; Cremades, E.; Barragan, F.; Alvarez, S. Covalent radii revisited. Dalton Trans. 2008, 21, 2832-2838. [CrossRef] [PubMed]

94. Boys, S.F.; Bernardi, F. The calculation of small molecular interactions by the differences of separate total energies. Some procedures with reduced errors. Mol. Phys. 1970, 19, 553-566. [CrossRef]

(C) 2020 by the authors. Licensee MDPI, Basel, Switzerland. This article is an open access article distributed under the terms and conditions of the Creative Commons Attribution (CC BY) license (http://creativecommons.org/licenses/by/4.0/). 